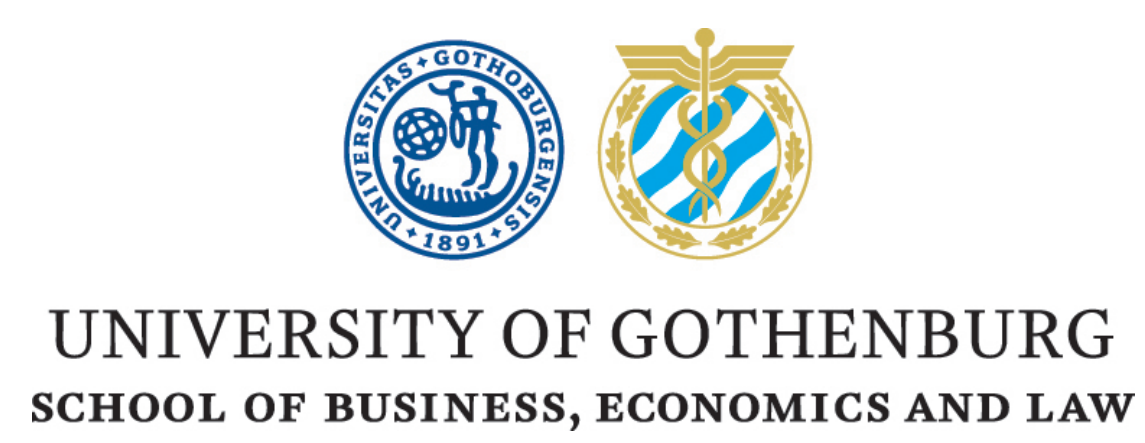

Master Degree Project in Economics

\title{
Electric Vehicle Adoption in Sweden and the Impact of Local Policy Instruments
}

Lina Trosvik and Filippa Egnér

Supervisor: Jessica Coria

Graduate School 


\begin{abstract}
A transition towards a higher share of electric vehicles has the potential to significantly reduce greenhouse gas emissions. The adoption rate of electric vehicles in Sweden is however relatively slow and varies substantially across municipalities. This thesis empirically examines the impact of local policy instruments designed to promote the adoption of electric vehicles. We use panel data between 2010 and 2016 to estimate the effect of local policy instruments on the share of newly registered battery electric vehicles in Swedish municipalities. We find that an increased number of public charging points increases the adoption rate, especially in urban municipalities. The results further suggest that public procurement of battery electric vehicles has the potential to be an effective policy instrument. Finally, we find that by adjusting policy instruments to the specific characteristics of municipalities and making them visible to the public, their effectiveness can be increased.
\end{abstract}

Keywords: electric vehicles, BEV, policy instruments, technology adoption, charging infrastructure, parking benefits, public procurement

2017-05-30

Filippa Egnér

Lina Trosvik

Supervisor: Jessica Coria 


\section{Acknowledgements}

We would like to express our appreciation towards our supervisor Jessica Coria for valuable comments throughout the process. We would also like to thank Magnus Hennlock at IVL for the interesting discussion and input. We are further grateful to the Swedish municipalities for taking their time to answer our questionnaire. Finally, thanks to our families and friends for supporting us throughout the process. 


\section{Contents}

1 Introduction 1

2 Background 3

2.1 Literature review . . . . . . . . . . . . . . . . . . . . . . . 3

2.2 Diffusion theory and barriers to EV technology adoption . . . . . . . . . 5

$\begin{array}{llr}3 & \text { Theoretical framework } & 7\end{array}$

4 Data and econometric strategy 10

4.1 Description of data . . . . . . . . . . . . . . . . . . . . . . 10

4.2 Econometric strategy . . . . . . . . . . . . . . . . . 15

4.3 Limitations . . . . . . . . . . . . . . . . . . . . . . . . 18

5 Results and analysis $\quad 20$

5.1 Testing Hypothesis $1 \ldots \ldots \ldots$. . . . . . . . . . . . . . . . . . . .

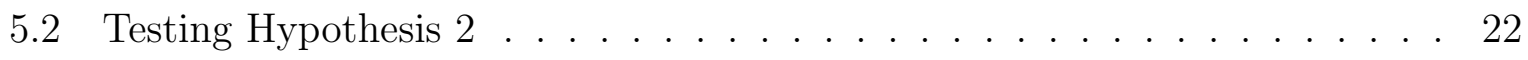

5.3 Robustness and sensitivity checks . . . . . . . . . . . . . 25

6 Discussion $\quad 28$

7 Conclusion $\quad 31$

8 References 33

$\begin{array}{ll}\text { Appendicies } & 36\end{array}$

A. Descriptive statistics . . . . . . . . . . . . . . . . . . 36

B. Robustness . . . . . . . . . . . . . . . . . . . . . . 38

C. Instrumental Variables regression _ . . . . . . . . . . . . . . . . . 41 


\section{List of Acronyms}

$\begin{array}{ll}\text { AVKT } & \text { Average Vehicle Kilometres Travelled } \\ \text { DoI } & \text { Diffusion of Innovation } \\ \text { FE } & \text { Fixed Effects } \\ \text { GHG } & \text { Greenhouse gases } \\ \text { IV } & \text { Instrumental Variable } \\ \text { OLS } & \text { Ordinary Least Squares } \\ \text { OVB } & \text { Omitted Variable Bias } \\ \text { RE } & \text { Random Effects } \\ \text { TCO } & \text { Total Cost of Ownership }\end{array}$

\section{Description of vehicle types}

BEV - Battery Electric Vehicle:

A vehicle that runs exclusively on electricity using an electric motor and an on-board battery which is charged by plugging it into a charging point (IEA, 2013).

EV - Electric Vehicle:

A general term used to describe any vehicle that uses an electric motor (IEA, 2013).

HEV - Hybrid Electric Vehicle:

A vehicle that combines a conventional internal combustion engine with an electric motor. Although these vehicles have an electric motor and battery, they cannot be plugged in and recharged. Instead, their batteries are charged from capturing energy that is normally wasted in conventional vehicles (IEA, 2013).

ICEV - Internal Combustion Engine Vehicle:

A vehicle using an internal combustion engine, typically fed with fossil fuels such as petrol or diesel. Currently, internal combustion engines are the dominant power source for vehicles (IEA, 2013).

PHEV - Plug-in Hybrid Electric Vehicle:

A vehicle similar to a HEV in having an internal combustion engine in addition to an electric motor, except a PHEV has higher battery capacity and can be recharged by plugging it into a charging point. A PHEV is further capable of using electricity as its primary engine source, while the internal combustion engine typically serves as a back-up when the battery is depleted (IEA, 2013). 


\section{Introduction}

Climate change is one of the greatest challenges of today and the reduction of emissions from greenhouse gases (GHG) is therefore essential. Currently in Sweden, the transport sector accounts for about one quarter of the total GHG emissions (Swedish Energy Agency, 2017) and in order to reduce these emissions, Sweden has set a target to achieve a fossil independent vehicle fleet by 2030 (SOU 2013:84). ${ }^{1}$ Depending on the source of electricity, a transition towards Electric Vehicles (EVs) has the potential to reduce GHG emissions and Sweden has therefore implemented several policy instruments to increase the EV adoption. Although the number of EVs is increasing in Sweden, the adoption rate is slow in comparison with other similar countries (Harrysson et al., 2015). Furthermore, there is a significant variation in the adoption rate of EVs across municipalities, despite the fact that financial incentives for EVs are the same. According to the Swedish National Institute of Economic Research (2013), the Swedish adoption rate of EVs is not sufficiently high in order to achieve the target by 2030, and the Swedish Energy Agency (2016) argues that there is a need for more detailed information about the driving forces affecting the adoption of EVs.

The aim of this thesis is therefore to contribute to the understanding of EV adoption by empirically examining its determinants. We focus on Battery EVs (BEVs) and examine the impact of local policy instruments designed to promote the adoption at a municipal level. The local policy instruments in Sweden include parking benefits and public charging infrastructure. In addition to these existing policy instruments, we also investigate whether public procurement of BEVs has the potential to increase the BEV adoption.

Our choice to focus on BEVs is motivated by the fact that they are highlighted as one of the most attractive technology alternatives to Internal Combustion Engine Vehicles (ICEV) in order to achieve fossil independence and a more energy efficient transport sector (Swedish Energy Agency, 2014; IEA, 2016). Compared to other EV types, BEVs have the potential to lower GHG emissions to a higher extent since they do not require any petroleum fuel. The emissions instead depend on the power source and since over 90 percent of the electricity production in Sweden is generated from renewable or nuclear sources (Statistics Sweden, 2017), the GHG emissions from BEVs are low. On a local level, BEVs also bring benefits such as air quality improvements and reduced noise (IEA, 2016). However, barriers such as high costs, limited battery capacity, and dependence on charging infrastructure are limiting the widespread diffusion of the EV technology (Axsen

\footnotetext{
${ }^{1}$ Fossil independent vehicle fleet is defined as vehicles not being dependent on fossil fuels.
} 
et al., 2010; Egbue \& Long, 2012; Leiby \& Rubin, 2004). Studies further suggest that imperfect information and limited knowledge about EVs contribute to slow diffusion rates (Brown, 2001; Sierzchula et al., 2014). These barriers can be connected to literature of technology diffusion, which suggests that perceptions of an innovation's characteristics, such as the level of relative advantage and uncertain benefits, determine its diffusion rate (Rogers, 2003). Using theory of technology diffusion to understand the barriers is thus helpful when analysing the impact of local incentives on BEV diffusion.

Related literature has in several countries found both nationally implemented financial incentives (e.g. Beresteanu \& Li, 2011; Chandra et al., 2010; Gallagher \& Muehlegger, 2011; Sierzchula et al., 2014) and locally implemented policy instruments (Mersky et al., 2016) to have a positive impact on EV adoption. However, the effectiveness of the Swedish national financial instruments promoting EVs are found to be weak (Harrysson et al., 2015; Huse \& Lucinda, 2014), and the local policy instruments have, to our knowledge, not previously been empirically examined. By taking advantage of the municipal variation in BEV adoption rates and local policy instruments in Sweden, this thesis is the first to causally investigate the impact of local policy instruments on the BEV adoption. Since municipalities with different characteristics face different barriers to BEV diffusion, this thesis also examines the impact of local policy instruments across sub-samples of municipalities. As the Swedish Energy Agency (2016) is looking for this information, our findings may be relevant for policy makers when designing policies for increased BEV adoption. Moreover, this thesis further contributes to the literature by using a new data set, in which some parts are collected through a questionnaire sent to all Swedish municipalities.

We present and build on a behavioural utility function for vehicle demand and specify hypotheses based on the theoretical framework and related literature. We use crossmunicipality panel data between 2010 and 2016 and by using the Fixed Effects estimator, we are able to control for heterogeneous municipal-specific effects. By using the share of newly registered BEVs as dependent variable, we find that public charging infrastructure has a positive and significant impact on the BEV adoption, where the economic significance is highest in urban municipalities. The results further suggest that municipalities with a higher number of municipally owned BEVs are associated with significantly higher overall BEV shares, especially in rural municipalities. Therefore, implementing a policy instrument of public procurement of BEVs can be argued to have the potential to be an effective instrument to increase the BEV adoption. The impact of parking benefits on BEV adoption is also found to be positive, but not as robust. Suggested by our findings, adjusting policy instruments to the specific conditions of municipalities and making them 
visible for the public, it can increase their effectiveness. Finally, the results indicate that the adoption of BEVs has been increasing over time, which is consistent with technology diffusion theory.

The thesis is structured as follows. Section 2 provides a literature review of previous research in the area and also includes a section covering relevant diffusion theory and barriers to EV technology adoption. Section 3 presents the theoretical framework leading up to the hypotheses to be tested. Section 4 presents the data and the econometric strategy. Section 5, 6, and 7 present the results, discussion, and conclusions, respectively.

\section{Background}

\section{$2.1 \quad$ Literature review}

The effect of financial policy instruments promoting EVs has previously been examined by a number of empirical studies. Diamond (2009) examines the impact of government incentives on Hybrid EV (HEV) adoption by using data of the US states between 2001 and 2006. By estimating fixed, random, and between effects models, he finds gasoline price to be a significant driver, while government incentives are found to have a weaker effect. Consistent with Diamond (2009), Beresteanu and Li (2011) also find gasoline price to be a driver of HEV adoption. Other studies find evidence that financial incentives lead to significantly higher EV sales (e.g. Chandra et al., 2010; de Haan et al., 2007; Gallagher \& Muehlegger, 2011). In Sweden, previous studies have only to a limited extent examined the impact of policy instruments promoting EVs. Huse and Lucinda (2014) examine the Swedish national green car rebate program and find that, even though it contributes to increased market shares of 'green' vehicles, the cost-effectiveness is indicated to be more doubtful. Chandra et al. (2010) study the tax rebate program in Canada and find, similar to Huse and Lucinda (2014), that the rebate program mainly subsidise consumers who would have bought HEVs regardless of the rebate.

Empirical studies examining factors affecting EV uptake are limited because the stock of EVs, both globally and in Sweden, only began to increase considerably after 2010 (IEA, 2016). Therefore, several previous studies analysing the demand for EVs use discrete choice models (Axsen et al. 2009; Bolduc et al., 2008; Brownstone et al., 2000; Hidrue et al., 2011) or simulation models (Eppstein et al., 2011; Mau et al., 2008; Mueller \& de Haan, 2009) based on survey data, rather than models consisting of sales data. For example, simulation results by Eppstein et al. (2011) indicate Plug-in HEV (PHEV) market sales to be significantly enhanced by financial incentives and low electricity prices. 
Findings by Langbroek et al. (2016), based on a stated choice experiment, also show that policy instruments have a positive influence on EV adoption. Langbroek et al. (2016) further argue that use-based policy instruments, such as free parking or access to bus lanes, are efficient alternatives to financial incentives.

Sierzchula et al. (2014) add to the literature by examining how socio-economic factors and charging infrastructure, in addition to financial incentives, influence the EV adoption. Using sales data of BEVs and PHEVs, they perform a cross-country analysis and find that financial incentives and charging infrastructure are significant factors explaining a country's EV market share. However, Sierzchula et al. (2014) lack the time aspect of the analysis as they only use data for 2012 and they are further not able to investigate how the heterogeneous allocation of charging infrastructure within a country influences the EV adoption. In an empirical study even more closely related to ours, Mersky et al. (2016) aim to identify determinants of BEV adoption at a regional and a municipal level in Norway. They find access to charging infrastructure, proximity to major cities, and income to have significant and positive effects on BEV adoption. Besides performing our analysis in the new setting of Swedish municipalities, we are improving several aspects of the econometric approach used by Mersky et al. (2016). First, by using data with panel structure, we are able to capture the time dimension in addition to the cross-sectional dimension, and thus better control for individual heterogeneity. By capturing the time dimension, we are able to examine how policies have affected the BEV diffusion over time. Second, by using the share of BEV sales as dependent variable, rather than the BEV sales per capita, we are able to control for exogenous shocks on the vehicle market. Finally, by including parking benefits and a proxy for public procurement of BEVs as explanatory variables, it enables us to examine the impact of additional local policy instruments.

In a qualitative study by Bakker and Trip (2013), the main finding is that knowledge and experience of driving EVs are important in order to increase the EV adoption. They argue that by having municipalities as lead users of EVs, it can communicate to the public that the municipality supports the technology. Public procurement may thus promote the use of BEVs. We provide evidence of such an effect by empirically investigating how a potential policy instrument of public procurement of BEVs is expected to affect the overall municipality BEV share.

This thesis contributes to the literature by providing a detailed assessment of the role of local instruments and other potential drivers on the BEV adoption rate. By using recent sales data, it adds to the literature, especially since the data set in this thesis has not previously been used to analyse this question. The impact of charging infrastructure as a policy instrument promoting EVs has only to a limited extent been examined in 
previous empirical studies (Mersky et al., 2016; Sierzchula et al., 2014). Furthermore, both Sierzchula et al. (2014) and Mersky et al. (2016) omit the important aspect of potential reversed causality between EV uptake and charging points, which this thesis therefore makes an attempt to address. Additionally, most previous studies evaluating the effect of EV-promoting policies are based on HEV sales data. Since BEVs are technologically more different from the dominant ICEVs than HEVs, the adoption is related to greater levels of uncertainty for consumers. Therefore, the results examining the BEV adoption are likely to be different from those of HEV adoption (Sierzchula et al., 2014).

\subsection{Diffusion theory and barriers to EV technology adoption}

The diffusion of an innovation is the process through which it is communicated over time among individuals in a social system. Getting a new innovation widely adopted often requires a lengthy time period, even if the innovation has obvious advantages (Rogers, 2003). Therefore, how to speed up the rate of adoption is a common issue related to the diffusion of new innovations, especially for new environmentally beneficial innovations (Brown, 2001). Rogers (2003) aims to explain how and when individuals adopt innovations using his Diffusion of Innovation (DoI) model, first developed and published in 1962. According to Rogers (2003), the perception of an innovation's characteristics determines its rate of diffusion. In general, innovations that are perceived by individuals as having greater relative advantage, compatibility, trialability, observability, and less complexity will have a higher diffusion rate than other innovations (Rogers, 2003). We therefore use the DoI model to get a deeper understanding of how factors affect the BEV diffusion rate.

The phenomenon of slow diffusion rates of environmentally beneficial innovations can be connected to the diffusion of EVs. Despite the potential benefits of EVs, there are obstacles inhibiting the widespread adoption of EV technology. The EV market share is currently small and according to Adner (2002), emerging technologies face more barriers as it often is difficult to compete with the price and performance of existing technologies. Previous studies have identified barriers limiting the diffusion of EVs, which can be closely connected to the DoI model. The main barriers affecting the consumers' decision of purchasing an EV are found to be battery range limitations resulting in range anxiety, high purchasing cost, and limited charging infrastructure (Axsen et al., 2010; Egbue \& Long, 2012; Leiby \& Rubin, 2004), which all can be connected to the relative advantage and compatibility of EVs. ${ }^{2}$ For example, the relatively few EV charging stations in Sweden

\footnotetext{
${ }^{2}$ Range anxiety refers to the fear drivers can experience from knowing that their battery can run out of charge.
} 
limit the compatibility and relative advantage of EVs since the number of charging points is not consistent with the existing experiences of ICEVs, with which it is possible to refuel almost anywhere.

According to Brown (2001), environmentally beneficial technologies often experience slow diffusion rates due to their commonly high purchasing prices. However, despite the high purchasing price for EVs, they in fact provide a lower Total Cost of Ownership (TCO) over the vehicle lifetime compared to that of ICEVs due to fuel savings and low maintenance costs (IEA, 2013). Furthermore, the price of electricity is in Sweden both cheaper and less volatile than petrol, bringing greater certainty about future operating expenses of the vehicle (IEA, 2013). The barrier of high costs is thus rather a source of imperfect information that confounds consumers and inhibit rational decision making. That is, instead of considering the TCO of a vehicle, individuals often rely too much on the purchasing price and less on the lifetime cost, making bounded rationality in the consumers' decision making a barrier to EV adoption (Brown, 2001; Sierzchula et al., 2014). Furthermore, Jaffe et al. (2005) suggest that the diffusion of new technologies is related, and limited, to the market failure of imperfect information. This is likely the case in Sweden since, according to a qualitative study by the Swedish Energy Agency (2014), the knowledge about EVs is generally low in Sweden, with only 11 percent of the people in the study considering themselves as having high or very high knowledge about EVs.

Imperfect information is related to uncertainty, which according to Rogers (2003) is an important barrier to diffusion of innovations. In the context of EVs, uncertainty can be connected to the aspects of complexity, trialability, and observability in the DoI model. The complexity aspect can in turn be connected to the barriers of limited battery range and charging infrastructure, which both can be perceived as more complex than for ICEVs. As investments in new technologies often are associated with uncertain benefits, a trialable and observable innovation therefore represents less uncertainty to potential adopters (Rogers, 2003). The trialability and observability of EVs further depend on the individual's possibility to access an EV in order to increase the knowledge and experience.

The importance of consumer acceptance of EVs is emphasised by the IEA (2009) as a factor determining the success of EV technologies. The diffusion process can further be accelerated through the neighbourhood effect, which implies that influence upon individuals from peer networks, who have already adopted, is likely to increase individuals' preferences and knowledge about EVs (Mau et al., 2008). As the consumers' perceptions of EVs during this learning process are affected by the number of individuals that already have adopted EVs, the early adopters create a positive externality (Jaffe et al., 2005).

The diffusion rate of new technologies, such as BEVs, is also influenced by policy 
instruments (Jaffe et al., 2005). Policy instruments are increasing the relative advantage of owning BEVs, and should according to the DoI model therefore speed up the diffusion rate. The incentives in Sweden are however relatively few in comparison with similar countries such as Norway and the Netherlands. Norway offers a wide range of incentives; for example, a number of reduced taxes, access to bus lanes for BEVs, exemption from several charges and fees, such as parking charges, bridge fees, fees at charging stations, and congestion charges (Harrysson et al., 2015). All of which can be expected to substantially increase the relative advantage of BEVs compared to ICEVs. The financial incentives provided for EVs in Sweden are also relatively weak in comparison with Norway (Harrysson et al., 2015). In 2012, the Swedish government introduced a subsidy for 'green' vehicles by providing vehicle buyers with a SEK 40,000 rebate, both for private and company buyers. BEV owners do further not pay the annual circulation tax for the first five years of ownership and finally, company purchased BEVs or PHEVs receive a tax discount (Harrysson et al., 2015). As these financial incentives are reducing the cost of BEVs, they are expected to increase the relative advantage of BEVs.

Leaving the literature of EV technology in specific, there are other studies examining the determinants of technology adoption in general or for other technologies and which have been found to follow the classical pattern of new technology diffusion (Caselli \& Coleman, 2001; Comin \& Hobijn, 2004; Comin \& Hobijn, 2010; Manuelli \& Seshadri, 2014). For instance, Comin and Hobijn (2004) examine the diffusion of more than 20 technologies using cross-country panel data, and find high levels of human capital and type of government to be important determinants of the technology adoption rate. These results are further consistent with those of Caselli and Coleman (2001), who use cross-country panel data to investigate the determinants of computer technology adoption. Although an extensive theoretical literature exists on technology diffusion, empirical applications are scarcer. By empirically study the diffusion of EVs, we bridge the gap between the literatures of EV adoption and the theoretical literature of technology diffusion.

\section{Theoretical framework}

In order to examine factors influencing the diffusion of BEVs at a municipal level, we first model individual consumer behaviour for vehicle purchasing. We build upon a general behavioural utility function for vehicle demand, first developed by Berry et al. (1995), and extended by Diamond (2009) and Beresteanu and Li (2011). Consumers are assumed to be utility maximising and can, for simplicity, be assumed to choose between a BEV and an ICEV. Although the theoretical specification allows some of the utility determinants 
to vary over time, we suppress the time subscript, $t$, in order to save notation. We let $i$ denote a consumer and $j$ denote a vehicle, for which the choice set consists of a BEV and an ICEV. In a given time period, the utility of consumer $i$ from purchasing vehicle $j$ is defined as

$$
u_{i j}=f\left(\theta_{j}, x_{j}, p_{j}, \varphi_{i}\right)+\epsilon_{i j}
$$

where $\theta_{j}$ is a vector of national and local policy instruments related to vehicle $j ; x_{j}$ is a vector of vehicle attributes for vehicle $j ; p_{j}$ is the price of vehicle $j ; \varphi_{i}$ is a vector of preferences and socio-economic characteristics of consumer $i$. The preferences of a consumer are assumed to be affected by factors such as environmental awareness, geographical characteristics, the social network, and previous experiences. Additionally, $\epsilon_{i j}$ is an error term containing random taste shocks and other features of vehicle demand; for example, expectations of future fuel prices, vehicle $j$ 's second-hand market price, and the consumer's decision on when to buy a vehicle. In a given time period, consumer $i$ chooses to purchase a BEV if and only if

$$
u_{i, B E V} \geq u_{i, I C E V}
$$

The expression implies that, for a consumer to choose to purchase a BEV, the individual's utility from doing so must be higher than or equal to the utility from purchasing an ICEV. Based on the utility function in equation (1), we derive the aggregated demand function for vehicle $j$. For a given population, the aggregated demand for vehicle $j$ is defined as

$$
A_{j}=\left\{i: u_{i j} \geq u_{i r}\right\}, \quad \text { for } r=0, B E V, I C E V ; r \neq j
$$

where the aggregated demand, $A_{j}$, consists of the sum of consumers that have utilities resulting in the purchasing choice of vehicle $j ; r$ represents the vehicle alternatives, and $r=0$ represents the alternative of not purchasing any vehicle. The market share, $s_{j}$, of a given vehicle and a given population is further defined as

$$
s_{j}=f\left(\theta_{j}, x_{j}, p_{j}, \bar{\varphi}\right)+\epsilon_{j}
$$

The market share is still a function of the policy instruments, attributes, and price of an individual vehicle $j$, but the consumer characteristics, in terms of preferences and socio-economic factors, are now the characteristics of the overall population average, $\bar{\varphi}$.

We continue by assuming the populations to be represented by municipalities and the demanded vehicles to be BEVs. The supply of vehicle models for sale and their corresponding prices are assumed to not vary at a municipal level. Therefore, the vehicle attributes, $x_{j}$, and vehicle price, $p_{j}$, are omitted from the model. We further assume that 
the municipal-varying determinants of the BEV market share remain constant over a year, but can vary within municipalities between years. We therefore introduce the yearly time subscript, $t$, for determinants that vary within a given municipality between years. The market share of BEVs for a given municipality, $m$, at time $t$, can now be defined as

$$
B E V \_s_{m, t}=f\left(\theta_{m, B E V, t}, \bar{\varphi}_{m, t}\right)+\epsilon_{m, B E V, t} .
$$

Based on the presented theoretical framework, it can be concluded that the variation in BEV adoption across and within municipalities can be affected by various factors. To empirically examine how the variation in different factors affect the BEV adoption, the theoretical equation for BEV market share, in equation (5), will be used as the basis for the econometric model.

As stated in equation (5), policy instruments are expected to affect the municipality BEV share. Since this thesis is aiming to explain the adoption rate of BEVs at a municipal level, the national level instruments are excluded as they do not vary across municipalities. At the local level in Sweden, some municipalities have implemented a policy incentive of parking benefits for EVs (Harrysson et al., 2015). Being able to park an EV for free could increase the relative utility of owning a BEV and thus affect consumers' purchasing decisions. Another local policy instrument that may affect the incentives for purchasing a BEV is the availability of charging infrastructure (Sierzchula et al., 2014). A high number of charging points facilitates the charging of BEVs and thus decreases the disutility arising from the barriers related to owning a BEV. Finally, a potential policy instrument to promote BEVs is to implement regulations regarding public procurement of BEVs. Currently in Sweden, the regulation of public procurement states that municipalities need to consider the environmental impact of the vehicle's total lifetime when purchasing a new vehicle (SFS 2011:846). Even though the regulation does not currently state anything about BEVs specifically, some municipalities have nevertheless purchased BEVs to their own vehicle fleet. As empathised by the DoI model, knowledge and experience are important factors in the technology diffusion. Municipally owned BEVs therefore have the potential to communicate to the public that the municipality supports the technology (Bakker \& Trip, 2013), which in turn may encourage the public opinion towards BEVs. Hence, public procurement of BEVs as a policy instrument has the potential to speed up consumers' acceptance of BEVs and in turn affect their purchasing decisions. In order to examine these relationships, the following hypothesis will be tested:

Hypothesis 1: Local policy instruments, in the form of parking benefits, provision of public charging points, and public procurement, have a positive impact on the BEV adoption. 
The municipalities in Sweden have different geographical and demographical characteristics, which may influence the diffusion rate of BEVs. For example, since one of the main barriers to BEV diffusion is limited driving range, the average vehicle kilometres travelled in a municipality is expected to affect the utility of BEV ownership (IEA, 2009). Individuals living in rural areas are likely to travel longer distances compared to individuals living in urban areas, implying that the barrier of limited driving range may be more evident in rural municipalities. Provision of public charging points therefore has the potential to address this barrier. However, in large cities where people to a higher extent live in apartments rather than houses, charging infrastructure may be even more important since the convenience of charging at home may be limited (IEA, 2013). For individuals living in apartment buildings that lack charging points, the utility from purchasing a BEV is reduced, which inhibits the BEV diffusion. Similar to rural areas, individuals living in urban areas also rely on public charging, but for different reasons. Furthermore, the effect of parking benefits on BEV diffusion may also differ between municipalities, depending on the availability of parking places. The effect is likely to be higher in municipalities with limited and expensive parking compared to municipalities with cheaper and more easily available parking. Finally, the effect of municipally owned BEVs can also be expected to differ between different municipality types. In rural municipalities, an additional BEV may receive more public attention than in urban municipalities where the BEV may not stand out as much. By examining the impact of local policy instruments across subsamples of municipalities, it can contribute to the understanding of how barriers affect $\mathrm{BEV}$ adoption in different municipality types. In order to explore the challenges related to $\mathrm{BEV}$ adoption between different municipality types, we will examine the following hypothesis:

Hypothesis 2: Depending on how urban or rural municipalities are, the local policy instruments affect the BEV adoption to different degrees.

\section{Data and econometric strategy}

\subsection{Description of data}

In order to examine the hypotheses, we have collected annual data on a municipal level between 2010 and 2016. As there are 290 Swedish municipalities, the number of observations is 2,030 when taking the panel structure into account. Because each municipality is observed every year, we have a balanced panel data set. Table 1 presents and describes the variables that are used in the analysis. 
Table 1: Description of variables and data sources.

\begin{tabular}{lll}
\hline Variable & Description & Source \\
\hline BEV share & Share of newly registered passenger BEVs (\%) & Trafikanalys (2017) \\
Charging & No. of charging points per 1,000 inhabitants & Power Circle (2017) \\
Parking & Binary variable equal to 1 if parking benefits & Answers from questionnaire* \\
Procurement & No. of municipally owned BEVs per 1,000 inhabitants & Transportstyrelsen (2017) \\
Income & Average annual income in SEK thousands & Statistics Sweden (2017) \\
Education & Share of inhabitants with post-secondary education (\%) & Statistics Sweden (2017) \\
Green Party votes & Share of votes for the Green Party (\%) & Statistics Sweden (2017) \\
AVKT & Average Vehicle Kilometres Travelled (per day) & Trafikanalys (2017) \\
Pop. density & Population density (inhabitants per square kilometre) & Statistics Sweden (2017) \\
\hline
\end{tabular}

* We sent a questionnaire to all 290 Swedish municipalities to collect this information and received 265 replies.

The dependent variable is the share of newly registered BEVs as a percentage of all new passenger vehicle registrations. ${ }^{3}$ In contrast to the related study by Mersky et al. (2016), we are able to control for exogenous shocks on the vehicle market since we use the share of total registered vehicles, rather than the BEV sales per capita. Exogenous shocks can, for instance, affect the level of economic activity in the society, which in turn can affect the sales on the whole vehicle market.

The main explanatory variables of interest are those for the local policy instruments; public charging points, parking benefits, and the proxy for public procurement. The variable for charging represents the total number of public charging points per 1,000 inhabitants for each municipality each year. ${ }^{4}$ The variable for parking benefits is binary; representing whether municipalities have had free parking for BEVs or not for the specific years. The variable varies both between municipalities and over time. Since this data was unavailable, we collected this information by contacting all Swedish municipalities using a questionnaire. ${ }^{5}$ Hence, it is to our knowledge the first time the variable of parking benefits is used in an empirical analysis.

Since there currently is no specific regulation of public procurement of BEVs in Sweden, we instead use a proxy containing data of the total number of municipally owned BEVs per 1,000 inhabitants for each municipality each year. The proxy is used to examine tendencies of how public procurement can be expected to impact the overall BEV share

\footnotetext{
${ }^{3}$ The variable includes BEVs purchased by individuals and companies (municipally purchased BEVs excluded).

${ }^{4}$ Charging points can be divided into different types, depending on the charging time required, and the set of charging point types may affect the BEV adoption. However, this is beyond the scope of this thesis due to data unavailability.

${ }^{5} \mathrm{We}$ complemented the observations for the municipalities with missing replies by collecting the information in alternative ways, such as through their websites or by telephone.
} 
in the municipality. An alternative specification would be to express municipally owned BEVs as a share of total municipally owned vehicles, and thus control for municipalities that have few vehicles in general. However, since we are interested in analysing the effect of publicly visible BEVs on the BEV adoption, it is appropriate to express the variable per 1,000 inhabitants, rather than a share. Another advantage of this variable specification, except being able to control for scale, is that we can compare the estimated coefficient with that of the charging infrastructure. The proxy variable for public procurement may be inaccurate since there currently is no specific public procurement of BEVs. Therefore, we will not be able to investigate the effect of public procurement, but only the effect that the existence of municipally owned BEVs have on the overall BEV share in the municipality.

The control variables are based on findings of previous studies, in which they have been found to influence the adoption of EVs. First, the socio-economic factors of average income and education will be included. According to Diamond (2009), income relates to how individuals discount future energy cost savings and to the risk tolerance for new technologies. Low income individuals are expected to discount future energy cost savings to a higher extent since the initial vehicle purchasing price may be of higher importance. High income individuals are further expected to have a higher risk tolerance towards BEVs. These aspects suggest that higher average incomes should be associated with higher BEV shares. Furthermore, the adoption of new technologies is according to related literature associated with higher income and education levels (Caselli \& Coleman, 2001; Comin \& Hobijn, 2004; Egbue \& Long, 2012; Gallagher \& Muehlegger, 2011; Mersky et al., 2016).

Environmental awareness is also expected to affect the EV adoption. Depending on the municipalities' level of average consumer environmentalism, buying a 'green' vehicle can provide consumers with utility and thus increase the preferences for EVs (Heffner et al., 2005; Kahn, 2007). Similar to Kahn (2007), we use votes for the Green Party in the latest municipal election as a proxy for environmental awareness. The proxy may be slightly inaccurate since environmentally aware people do not necessarily vote for the Green Party. However, the same reasoning holds for all municipalities and the variable most likely reflects the environmental awareness to some degree. Finally, based on the DoI model and the identified barriers to BEV adoption, we include control variables for the municipalities' Average Vehicle Kilometres Travelled (AVKT) and population density.

Table 2 presents descriptive statistics of the variables for the full sample. For the dependent variable, the mean value of $\mathrm{BEV}$ share is 0.26 percent with a standard deviation of 0.60 , indicating a large variation across municipalities and time. Furthermore, as 
Table 2: Descriptive statistics of the variables for the full sample.

\begin{tabular}{llllll}
\hline & Mean & SD & Min & Max & Observations \\
\hline BEV share & 0.26 & 0.60 & 0 & 11.84 & 2,030 \\
Charging & 0.10 & 0.36 & 0 & 4.28 & 2,030 \\
Parking & 0.08 & 0.27 & 0 & 1 & 2,030 \\
Procurement & 0.02 & 0.08 & 0 & 1.54 & 2,030 \\
Income & 281.19 & 38.34 & 209.60 & 590.80 & 2,030 \\
Education & 0.19 & 0.06 & 0.10 & 0.47 & 2,030 \\
Green Party votes & 5.08 & 2.63 & 0.30 & 16.60 & 2,030 \\
AVKT & 31.59 & 5.27 & 17 & 44 & 2,030 \\
Pop. density & 143.98 & 510.22 & 0.20 & 5494.80 & 2,030 \\
\hline
\end{tabular}

Figure 1 below indicates, the share of BEVs in Sweden began to increase considerably after 2010, although it decreased between 2015 and 2016. ${ }^{6}$ The variation in BEV share is also increasing over time, suggesting that the diffusion rate of BEVs is different between municipalities and that some municipalities thus are better than others in promoting BEVs.

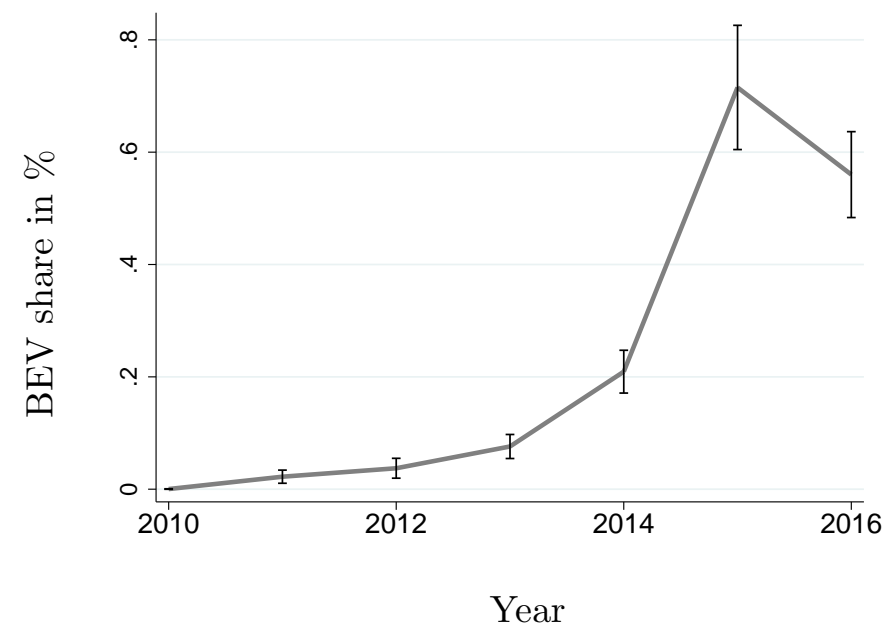

Figure 1: The average share of newly registered BEVs as a percentage of all registered passenger vehicles over time, where the error bars represent the 95 percent confidence interval in each year.

As shown in Table 2, the charging variable has a mean value of 0.10 charging points while the variable for municipally owned BEVs has a lower mean value of 0.02 , both measured per 1,000 inhabitants. The proportion of municipalities that provided parking benefits for EVs during the years of the study is 0.08 , which thus is rather low. Moreover, the standard deviations of the variables for charging, parking, and the procurement proxy are all indicating a relatively large variation in proportion to their mean values.

Figure 2 in Appendix A shows that the development of number of charging points

\footnotetext{
${ }^{6}$ The decrease in BEV share between 2015 and 2016 will be further mentioned in section 4.2.
} 
as well as of municipally owned BEVs, per 1,000 inhabitants, are increasing over time. Similar to the dependent variable, the variation between municipalities for these two variables are also increasing over time. Thus, the variables for BEV share, charging, and procurement show similar patterns in their data over time. The increased variation of BEV shares between municipalities over time might thus be connected to the increased variation in charging points and municipally owned BEVs over time. In contrast, the average development of the parking benefits variable shows a slightly negative trend over time, as shown in Figure 2 in Appendix A. As can be seen in the same figure, the AVKT variable also has a negative trend over time, indicating that the barrier of limited driving range should have decreased during these years. Moreover, the descriptive statistics for the control variables in Table 2 show no unexpected statistics.

To examine Hypothesis 2, we divide the sample into three sub-samples; urban, suburban, and rural municipalities. The sub-samples are divided based on a municipality classification used by SKL (2017), where the share of urban area, proximity to major cities, and commuting patterns are taken into account. ${ }^{7}$ Descriptive statistics of the variables for the sub-samples are presented in Table 3. It shows that the average BEV share is highest in the suburban sample and lowest in the rural sample. The urban sample has the lowest standard deviation, indicating that urban BEV shares deviate less from the overall average than suburban and rural municipalities.

Table 3: Descriptive statistics of the variables for the sub-samples.

Mean values with standard deviations in parentheses are presented.

\begin{tabular}{llll}
\hline & Urban sample & Suburb sample & Rural sample \\
\hline BEV share & $0.25(0.43)$ & $0.30(0.60)$ & $0.23(0.68)$ \\
Charging & $0.11(0.21)$ & $0.07(0.30)$ & $0.13(0.46)$ \\
Parking & $0.27(0.44)$ & $0.02(0.13)$ & $0.03(0.16)$ \\
Procurement & $0.03(0.12)$ & $0.02(0.08)$ & $0.02(0.05)$ \\
Income & $275.36(19.84)$ & $299.26(51.12)$ & $266.61(20.76)$ \\
Education & $0.22(0.06)$ & $0.20(0.07)$ & $0.15(0.03)$ \\
Green Party votes & $6.17(2.29)$ & $5.77(2.51)$ & $3.70(2.34)$ \\
AVKT & $29.15(3.54)$ & $31.72(6.44)$ & $33.00(4.23)$ \\
Pop. density & $178.17(624.11)$ & $244.24(641.60)$ & $21.37(37.15)$ \\
\hline Observations & 483 & 777 & 770 \\
No. of municipalities & 69 & 111 & 110 \\
\hline
\end{tabular}

The descriptive statistics in Table 3 further show that the average number of charging points per 1,000 inhabitants is highest in the rural sample and that it also has the highest

\footnotetext{
${ }^{7}$ More specifically, the urban sample consists of municipalities containing or are close to large cities. The suburban sample consists of municipalities containing or are close to medium sized cities, whereas the rural sample consists of small town and country-side municipalities.
} 
variation. As the number of people living in rural areas is relatively low, the high average of charging points is reasonable. The relatively high spread around the mean can further be an indication of an unclear pattern in the development of public charging infrastructure. It is further shown that the proportion of municipalities offering parking benefits is considerably higher in the urban sample. This is reasonable since many suburban and rural municipalities often offer free parking for all vehicle types. The average numbers of municipally owned BEVs per 1,000 inhabitants are similar across the sub-samples.

The descriptive statistics show that education and Green Party votes are on average highest in the urban sample, while average income is highest in the suburban sample. The higher average value of AVKT per day in the rural sample compared to the urban sample is reasonable since people can be expected to travel longer distances in rural areas. Although the average population density is lowest in the rural sample as expected, we would expect it to be highest in the urban sample rather than the suburban sample. The high standard deviation in the suburban sample could explain these unexpected values. Population density as a single measure may not fully reflect the urban degree of a municipality as it depends on the area of the municipality, which also could explain these unexpected values.

\subsection{Econometric strategy}

The panel structure of our data set has several advantages over a cross-sectional data set. It captures time variation in addition to cross-sectional variation and it allows us to control for unobserved cross-sectional heterogeneity (Baltagi, 2005). Except from the variables that vary with municipalities and time, there may be municipal- or time-invariant factors also affecting the BEV share. National policy instruments are nationwide and do not vary across municipalities. However, the reaction towards them may differ depending on time-invariant municipal-specific characteristics. For example, geographical factors and the history of political orientation of municipalities may affect the attitudes towards BEVs. The panel data analysis thus enables us to control for such time-invariant variables, whereas the omission of them in a cross-sectional study would have led to biased results (Baltagi, 2005). Our empirical approach is therefore based on models that take the panel structure into account, where the baseline model specification is defined as

$$
\begin{aligned}
& B E V \_s_{m t}=\mathbf{x}_{m t} \beta+u_{m t} \quad m=1, \ldots, N ; \quad t=1, \ldots, T \\
& u_{m t}=\alpha_{m}+\varepsilon_{m t}
\end{aligned}
$$

where $m$ denotes the cross-sectional dimension of municipalities, and $t$ denotes time. $B E V s_{m t}$ is the dependent variable BEV share, $\mathbf{x}_{m t}$ is a set of observable explanatory variables that are either time-varying or time-invariant, and $\beta$ is a vector of parameters. 
Panel data further allows us to divide the error component, $u_{m t}$, into an unobservable individual-specific effect, $\alpha_{m}$, and a remainder disturbance term of the idiosyncratic errors, $\varepsilon_{m t}$ (Baltagi, 2005; Wooldridge, 2010). Note that $\alpha_{m}$ is time-invariant and accounts for any municipal-specific effects that are not included in the regression. The idiosyncratic error term is assumed to be independent and identically normally distributed with homoscedasticity and no serial correlation; $\varepsilon_{m t} \sim \operatorname{IID}\left(0, \sigma_{\varepsilon}^{2}\right)$ (Baltagi, 2005). We therefore transform the dependent variable into natural logarithmic form in order to normalise the distribution of the residuals. This transformation is also appropriate since the distribution of the dependent variable is originally skewed. Histograms of the residuals before and after the logarithmic transformation are presented in Figure 3 in Appendix A. Moreover, the standard errors in different time periods for a given municipality are assumed to be correlated, while the standard errors across municipalities are assumed to be uncorrelated (Cameron \& Miller, 2015). We therefore adopt clustered robust standard errors to obtain accurate standard errors in the model with no concerns of heteroscedasticity or serial correlation. Clustering the standard errors at too low levels could result in too small standard errors and consequently, lead to incorrect inference (Cameron \& Miller, 2015). Since the level of variation of our explanatory variables of interest is at a municipal level, we cluster the standard errors at a municipal level.

Two conventional approaches when analysing panel data are the Fixed Effects (FE) and the Random Effects (RE) models. The RE model assumes zero correlation between the observed explanatory variables and the unobserved individual-specific effect; $E\left(\mathbf{x}_{m t} \alpha_{m}\right)=0$. In contrast, the FE model allows for the unobserved individual-specific effect to be correlated with the observed explanatory variables; $E\left(\mathbf{x}_{m t} \alpha_{m}\right) \neq 0$ (Wooldridge, 2010). Therefore, assumptions about $\alpha_{m}$ need to be made; whether it is treated as a fixed parameter to be estimated as in the FE model or as a random variable with $\alpha_{m} \sim \operatorname{IID}\left(0, \sigma_{\alpha}^{2}\right)$ as in the RE model. For both models, the strict exogeneity assumption, $E\left(\mathbf{x}_{m t} \varepsilon_{m t}\right)=0$, is underlying the models, implying that the explanatory variables are independent of $\varepsilon_{m t}$ for past, present, and future values (Wooldridge, 2010). Moreover, the correlation matrix of the variables, presented in Table 6 in Appendix A, shows no problematic correlations, in which the largest correlation is 0.66 between Green Party votes and Education. When investigating the assumptions of no multicollinearity and no large outliers, we do not identify any problems.

The FE model can be used when only analysing the impact of variables that vary over time, in which we are able to study the causes of changes within a municipality. All the unobserved time-invariant differences, $\alpha_{m}$, between municipalities are controlled for in the FE model since they are cancelled out in the estimation. Although the FE model 
addresses the problem of time-invariant Omitted Variable Bias (OVB), the problem of potential time-varying OVB remains (Stock \& Watson, 2012). Unlike the FE model, the RE model considers the variation across municipalities, and enables the inclusion of time-invariant explanatory variables. However, since time-invariant variables are not automatically controlled for in the RE model, it increases the risk of OVB if some timeinvariant variables are not included in the regression. Although the RE model leads to more efficient estimates, those estimates may be biased if the stronger assumptions associated with the RE model does not hold. Thus, there is a trade-off between bias and efficiency between the RE and the FE models (Dougherty, 2007).

Since the key consideration when choosing between a FE and a RE approach is whether $\alpha_{m}$ and the included explanatory variables are correlated, we test this using a Hausman test where the null hypothesis is that $\alpha_{m}$ is uncorrelated with the independent variables. The test is based on the differences between the RE and the FE estimates. Since the FE estimator is consistent while the RE estimator is inconsistent when $\alpha_{m}$ and $\mathbf{x}_{m t}$ are correlated, a statistically significant difference is interpreted as evidence against the $\mathrm{RE}$ model (Wooldridge, 2010). The Hausman test indicates that the preferred model in our case is the FE model. The RE model further assumes that the observations are randomly drawn from a given population (Baltagi, 2005), which is not reasonable to assume in our case since we examine the whole population. However, while keeping in mind that the FE model is indicated to be the most appropriate one, both the FE estimates and the RE estimates will be reported in order to fully explore the panel data. In cases where the explanatory variables do not vary much over time, the FE methods can lead to imprecise estimates. Therefore, reporting the RE estimations in addition to the FE estimations enables us to learn more about the population parameters (Wooldridge, 2010). Finally, the FE model is estimated with the Ordinary Least Squares (OLS) method and generates the within-estimates, while the RE model is estimated by the Generalized Least Squares estimator producing a matrix-weighted average of the between and within results (StataCorp, 2013).

The variables from Table 1 are included into our baseline model specification in equation (6) and forming the model specification in equation (7). This is the main model we use when estimating the regressions, both for the full sample and the sub-sample regressions. ${ }^{8}$

\footnotetext{
${ }^{8}$ In order to examine whether the results are sensitive to the particular model specification, we also estimate alternative models to compare the results. These are found in Appendix B and discussed in section 5.3.
} 


$$
\begin{aligned}
\text { ln_BEV_s }_{m t} & =\beta_{0}+\beta_{1} \text { ln_Charging }_{m t}+\beta_{2} \text { Parking }_{m t}+\beta_{3} \text { In_Procurement }_{m t} \\
& +\beta_{4} \text { Income }_{m t}+\beta_{5} \text { Education }_{m t}+\beta_{6} \text { Green Party votes }_{m t} \\
& +\beta_{7} \text { AVKT }_{m t}+\beta_{8} \text { Pop.density }_{m t}+\beta_{9} \text { Year }_{t}+u_{m t}
\end{aligned}
$$

The variables for charging infrastructure and public procurement are transformed into natural logarithmic form in order to better fit the linear model. In addition, the log-log specification allows the interpretation of the regression coefficients to be the elasticity in BEV share with respect to a percentage change in the variable for charging infrastructure and public procurement. The variable for parking benefits is not transformed into logarithmic form since it is binary.

By including time dummies to the model, it is possible to control for any time fixed effects such as unexpected variation or certain events that may affect the BEV share at a national level. For example, the decrease in average BEV share between 2015 and 2016, shown in Figure 1, could potentially be due to some shock affecting only the BEV market. If time dummies are statistically significant, they should be included in the econometric model (Wooldridge, 2010). However, time dummies are in our estimated models statistically insignificant and instead, a yearly time trend variable is included to capture the overall increase in BEV share over time. The estimated time trend coefficient is thus the annual change in BEV share, holding constant the influence of the other variables (Cameron, 2005). In our context, the time trend variable is appropriate to include as it acts as a proxy for the diffusion theory, which helps explain the adoption rate of BEVs over time. Factors included in this proxy are, for example, technological innovation of BEVs, greater supply of BEV models, national level policy instruments, and growing visibility of BEVs for the general public. The overall increase of people's knowledge and awareness of BEVs over time are also factors captured by the time trend.

\subsection{Limitations}

A limitation with using sub-samples is that there may be structural differences in municipality characteristics, other than just being urban, suburban, and rural, affecting the BEV share. For instance, these different categories of municipalities may be linked to certain political opinions or attitudes towards new technology. Therefore, when interpreting the results, it is important to have in mind that characteristics of the sub-samples, other than just the share of urban area, proximity to major city, and commuting patterns, may influence the results. However, by using these sub-samples it enables us to analyse tendencies of potential differences that are due to the factors which are the basis in SKL's 
(2017) classification of municipalities, presented in section 4.1.

We are not including fuel price in our analysis, even though some previous studies (Beresteanu \& Li, 2011; Diamond, 2009) have found it to be a significant determinant of the EV share. Since the fuel price variables in Sweden are mainly varying over time and not across municipalities, they are likely to be highly correlated with the time trend variable, and are due to potential multicollinearity not appropriate to include. During the years of the study, the carbon tax has increased (SPBI, 2017) while the electricity price has decreased (Nord Pool, 2017). Hence, these trends imply that the barriers of $\mathrm{BEV}$ adoption have decreased and that the relative advantage of BEVs has increased over time. By including the time trend variable in the analysis, it enables us to partly capture these fuel price trends in addition to other variables that only vary over time. A limitation with the time trend variable is that we cannot isolate the specific effects of the different factors captured by the time trend variable. However, it does not affect our ability to test the hypotheses of this thesis.

One potential source of endogeneity in our FE models is omitted variables in the form of municipal time-varying characteristics correlating with both BEV share and any of the control variables. For example, time-varying political aspects in municipalities could potentially bias the results since it may correlate with both Green Party votes and BEV share. In the RE models, the omission of both time-varying and time-invariant characteristics are potential sources of endogeneity, which we have in mind when interpreting the results.

The Supreme Administrative Court decided during the time period of our study that municipalities are not allowed to exempt 'green' vehicles, including BEVs, from parking fees. The Court reached the decision that it violates the Local Government Act to favour 'green' vehicle owners. The judgement was first applied to the municipality of Gotland in 2014 (HFD 2014 ref 57), and works as a guide to the rest of the country. Therefore, several of the municipalities that offered parking benefits towards BEVs in the earlier period of our analysis have stopped doing so due to the court case, while some have continued to offer them. This will thus have some implications for our analysis since it limits the ability to observe the actual effect of parking benefits on the BEV share. 


\section{$5 \quad$ Results and analysis}

\section{$5.1 \quad$ Testing Hypothesis 1}

Table 4 below presents the regression results testing Hypothesis 1, which is that local policy instruments are expected to affect the municipality BEV share positively. As discussed in section 4.2, we present regression results for both the FE and the RE estimators, although we focus on the FE estimations because of the Hausman test results. The first two models, (1) and (2), only include the main explanatory variables of interest and a time trend variable. Model (3) and (4) are based on equation (7), which includes the control variables.

Table 4: Regressions with full sample, using BEV share (ln) as dependent variable.

\begin{tabular}{|c|c|c|c|c|}
\hline & (1) & $(2)$ & (3) & (4) \\
\hline & $\mathrm{FE}$ & $\mathrm{RE}$ & $\mathrm{FE}$ & $\mathrm{RE}$ \\
\hline \multicolumn{5}{|l|}{ Local incentives } \\
\hline \multirow[t]{2}{*}{ Ln Charging } & $0.273^{* * *}$ & $0.288^{* * *}$ & $0.273^{* * *}$ & $0.273^{* * *}$ \\
\hline & $(0.055)$ & $(0.047)$ & $(0.053)$ & $(0.043)$ \\
\hline \multirow[t]{2}{*}{ Parking } & 0.096 & $0.156^{* * *}$ & 0.023 & -0.012 \\
\hline & $(0.118)$ & $(0.059)$ & $(0.103)$ & $(0.056)$ \\
\hline \multirow[t]{2}{*}{ Ln Procurement } & $0.225^{* * *}$ & $0.240^{* * *}$ & $0.270^{* * *}$ & $0.230^{* * *}$ \\
\hline & $(0.081)$ & $(0.079)$ & $(0.077)$ & $(0.072)$ \\
\hline \multicolumn{5}{|l|}{ Control variables } \\
\hline \multirow[t]{2}{*}{ Income } & & & $0.026^{* * *}$ & $0.003^{* * *}$ \\
\hline & & & $(0.007)$ & $(0.001)$ \\
\hline \multirow[t]{2}{*}{ Education } & & & 1.483 & $0.969^{*}$ \\
\hline & & & $(6.737)$ & $(0.519)$ \\
\hline \multirow[t]{2}{*}{ Green Party votes } & & & $0.088^{* * *}$ & $0.027^{* *}$ \\
\hline & & & $(0.033)$ & $(0.011)$ \\
\hline \multirow[t]{2}{*}{ AVKT } & & & $-0.023^{* * *}$ & $-0.016^{* * *}$ \\
\hline & & & $(0.008)$ & $(0.004)$ \\
\hline \multirow[t]{2}{*}{ Pop. density } & & & 0.001 & $-8.22 \mathrm{e}-05^{* * *}$ \\
\hline & & & $(0.001)$ & $(2.21 \mathrm{e}-05)$ \\
\hline \multirow[t]{2}{*}{ Time trend } & $0.234^{* * *}$ & $0.232^{* * *}$ & 0.025 & $0.189^{* * *}$ \\
\hline & $(0.012)$ & $(0.012)$ & $(0.041)$ & $(0.013)$ \\
\hline \multirow[t]{2}{*}{ Constant } & $-472.100^{* * *}$ & $-466.700^{* * *}$ & -58.380 & $-380.600^{* * *}$ \\
\hline & $(23.700)$ & $(23.220)$ & $(81.790)$ & $(25.600)$ \\
\hline Observations & 2,030 & 2,030 & 2,030 & 2,030 \\
\hline No. municipalities & 290 & 290 & 290 & 290 \\
\hline$R^{2}$ & 0.463 & 0.422 & 0.486 & 0.472 \\
\hline
\end{tabular}

The estimated coefficient for charging infrastructure is positive and significant across both estimators and all model specifications. The statistical significance is high at a one percent level and the magnitude of the coefficient stays robust across the models. The coefficient is interpreted as an elasticity due to the log-log specification. Thus, if increasing 
the number of charging points (per 1,000 inhabitants) with one percent, the municipality $\mathrm{BEV}$ share is expected to increase by approximately 0.3 percent on average. The increase in BEV share is hence inelastic, but positive. According to this result, a higher number of charging points has a positive effect on the BEV adoption. This is reasonable since, as hypothesised, a higher number of charging points decrease the barriers of range anxiety and limited ability to charge at home, which in turn increase the relative advantage and utility of BEVs. Furthermore, the finding is in line with the previous studies by Mersky et al. (2016) and Sierzchula et al. (2014), in which charging infrastructure is found to be an important predictive factor. For instance, in the cross-country analysis by Sierzchula et al. (2014), each additional charging station per 100,000 residents that a country adds is found to increase its EV market share by 0.12 percent. The magnitude is however difficult to compare with our result due to different variable specifications.

The estimated coefficient for parking benefits is not as robust as that for charging points, and when including the control variables it becomes insignificant with both estimators. However, it is positive and significant at a one percent level in model (2). The magnitude of 15.6 percent is interpreted as the percentage change in BEV share associated with a municipality offering parking benefits compared to not offering it. ${ }^{9}$ One explanation to the insignificant coefficient in the FE model is that it takes the within variation into account, while the RE estimator takes the across-municipality variation into account. Since parking benefits varies more across than within municipalities, the regression results are reasonable. Moreover, the FE and RE models report coefficients with different magnitudes for some variables, and the FE standard errors are substantially larger. This is common in $\mathrm{FE}$ models, especially when the predictor variable varies little over time (Allison, 2009), and it could further explain the higher statistical significance of the RE coefficients. However, the RE estimates may be biased due to a potential correlation between the explanatory variables and some unobserved time-invariant variable affecting the BEV share. This could explain the outcome differences since unobserved time-invariant variables are, as mentioned, controlled for in the FE estimations.

The estimated coefficient for the procurement proxy is positive and significant at a one percent level across all models. If increasing the number of municipally owned BEVs (per 1,000 inhabitants) with one percent, the municipality BEV share is expected to increase by approximately $0.2-0.3$ percent on average. Similar to the estimated effect of charging infrastructure, the increase in BEV share is inelastic. As hypothesised, municipalities as lead users of BEVs are thus indicated to affect the overall BEV share positively. This result is further in line with the DoI model, in which the diffusion rate of technology

\footnotetext{
${ }^{9} 0.156 \times 100=15.6 \%$ (due to log-level specification of the parking variable).
} 
is expected to be higher when knowledge and acceptance are greater. Moreover, the coefficient magnitudes of the variables for charging and procurement are comparable since they both are continuous per 1,000 inhabitants and transformed into logarithmic form. Comparing these elasticities, they are indicated to have similar effects on the BEV share, around 0.3 percent.

All the statistically significant control variables show the expected signs and are in line with most findings of previous literature, mentioned in section 4.1. For example, higher income, education, and environmental awareness are related to higher BEV shares, while longer AVKT are related to lower BEV shares. The positive relationship between education and BEV share is in line with the survey based study by Egbue \& Long (2012), which found educated individuals to be more likely to adopt EVs. The negative relationship between AVKT and BEV sales is consistent with the result of Mersky et al. (2016), which found their equivalent AVKT variable to be negatively related with BEVs. In line with the barrier of limited driving range affecting the consumers' purchasing decision (Axsen et al., 2010; Egbue \& Long, 2012; Leiby \& Rubin, 2004), this finding can be interpreted as BEVs being less suitable for individuals that on average travel long distances. The positive and significant coefficient of average municipal income is expected, due to the identified barrier of high initial purchasing cost of BEVs. Finally, the time trend coefficient is positive and significant in most models, indicating that time positively affects the BEV share. It thus demonstrates the importance of time to the adoption of BEVs, which is an essential aspect in the DoI model. As discussed in section 4.2, the time trend acts as a proxy for the diffusion theory and it captures factors that vary over time but not across municipalities. Since the coefficient is positive, one interpretation is that decreased barriers and increased relative advantage for BEVs have had a positive effect on the BEV share.

The reported R-squared for the FE models represents the adjusted R-squared for the within variation, whereas the reported R-squared for the RE models is the overall $\mathrm{R}$ squared. The FE and RE models explain approximately 40 - 50 percent of the within and overall variation, respectively, of the dependent variable. As expected, the R-squared measures increase when the control variables are included.

\subsection{Testing Hypothesis 2}

Table 5 below presents the sub-sample regression results testing Hypothesis 2, which is that the effect of local policy instruments is expected affect the municipality BEV share to different degrees depending on how urban or rural the municipalities are. Regressions 
based on the model specification in equation (7) are presented, both for the FE and RE estimations.

Table 5: Regressions using sub-samples and BEV share (ln) as dependent variable.

\begin{tabular}{|c|c|c|c|c|c|c|}
\hline & \multicolumn{3}{|c|}{ Fixed Effects } & \multicolumn{3}{|c|}{ Random Effects } \\
\hline & (1) & $(2)$ & $(3)$ & (4) & $(5)$ & $(6)$ \\
\hline & Urban & Suburb & Rural & Urban & Suburb & Rural \\
\hline \multicolumn{7}{|l|}{ Local incentives } \\
\hline \multirow[t]{2}{*}{ Ln Charging } & $0.397^{* * *}$ & $0.295^{* * *}$ & $0.203^{* *}$ & $0.315^{* * *}$ & $0.278^{* * *}$ & $0.172^{* * *}$ \\
\hline & $(0.090)$ & $(0.094)$ & $(0.081)$ & $(0.061)$ & $(0.072)$ & $(0.065)$ \\
\hline \multirow[t]{2}{*}{ Parking } & -0.109 & $0.339^{* * *}$ & 0.109 & 0.010 & $0.483^{* *}$ & -0.060 \\
\hline & $(0.092)$ & $(0.138)$ & $(0.253)$ & $(0.052)$ & $(0.218)$ & $(0.151)$ \\
\hline \multirow[t]{2}{*}{ Ln Procurement } & 0.092 & 0.144 & $0.383^{* *}$ & $0.154^{*}$ & 0.106 & $0.430^{* * *}$ \\
\hline & $(0.095)$ & $(0.128)$ & $(0.183)$ & $(0.087)$ & $(0.126)$ & $(0.155)$ \\
\hline \multicolumn{7}{|l|}{ Control variables } \\
\hline \multirow[t]{2}{*}{ Income } & 0.003 & $0.042^{* * *}$ & -0.008 & -0.002 & $0.004^{* * *}$ & -0.001 \\
\hline & $(0.012)$ & $(0.009)$ & $(0.010)$ & $(0.002)$ & $(0.001)$ & $(0.002)$ \\
\hline \multirow[t]{2}{*}{ Education } & 14.160 & -12.280 & 19.700 & 0.835 & -0.846 & $4.680 * * *$ \\
\hline & $(10.850)$ & $(8.284)$ & $(12.950)$ & $(0.623)$ & $(0.952)$ & $(1.463)$ \\
\hline \multirow[t]{2}{*}{ Green Party votes } & $0.109^{* *}$ & $0.167^{* * *}$ & 0.009 & $0.050^{* * *}$ & $0.040^{* * *}$ & 0.001 \\
\hline & $(0.053)$ & $(0.055)$ & $(0.036)$ & $(0.015)$ & $(0.015)$ & $(0.018)$ \\
\hline \multirow[t]{2}{*}{ AVKT } & $0.036^{* *}$ & $-0.030^{* * *}$ & $-0.031^{* *}$ & -0.003 & $-0.018^{* * *}$ & $-0.033^{* * *}$ \\
\hline & $(0.015)$ & $(0.011)$ & $(0.014)$ & $(0.011)$ & $(0.006)$ & $(0.009)$ \\
\hline \multirow[t]{2}{*}{ Pop. density } & $0.002^{* *}$ & 0.000 & $0.006^{* * *}$ & $5.43 \mathrm{e}-06$ & $-0.000^{* *}$ & 0001 \\
\hline & $(0.001)$ & $(0.001)$ & $(0.002)$ & $(5.34 \mathrm{e}-05)$ & $(5.25 \mathrm{e}-05)$ & $(0.001)$ \\
\hline \multirow[t]{2}{*}{ Time trend } & $0.162^{* *}$ & -0.028 & 0.124 & $0.226^{* * *}$ & $0.236^{* * *}$ & $0.107^{* * *}$ \\
\hline & $(0.063)$ & $(0.069)$ & $(0.078)$ & $(0.022)$ & $(0.021)$ & $(0.025)$ \\
\hline \multirow[t]{2}{*}{ Constant } & $-332.400^{* * *}$ & 45.220 & -250.700 & $-455.700^{* * *}$ & $-476.016^{* * *}$ & $-215.900^{* * *}$ \\
\hline & $(124.200)$ & $(136.900)$ & $(154.900)$ & $(44.290)$ & $(42.150)$ & $(49.350)$ \\
\hline Observations & 483 & 777 & 770 & 483 & 777 & 770 \\
\hline No. municipalities & 69 & 111 & 110 & 69 & 111 & 110 \\
\hline$R^{2}$ & 0.643 & 0.579 & 0.342 & 0.625 & 0.528 & 0.357 \\
\hline
\end{tabular}

Robust standard errors clustered at the municipal level in parentheses.

*** denotes significance at $1 \%$ level, ${ }^{* *}$ at $5 \%$ level, and $*$ at $10 \%$ level.

The estimated coefficient for charging infrastructure is positive and statistically significant at a one percent level in all sub-samples regressions, except for in model (3) where it is significant at a five percent level. The magnitude, and thus the economic significance, is higher in the urban sample than in the suburban and rural samples, both in the FE and RE regressions. As hypothesised, the local policy instrument of public charging infrastructure thus affects the BEV adoption to different degrees depending on how urban or rural municipalities are. One interpretation is that urban areas may be more dependent on available charging infrastructure in order to increase the BEV share. The barrier of limited ability to charge at home may thus be greater than the barrier of range anxi- 
ety, making public charging infrastructure especially important in urban areas. Another interpretation is that the barrier of limited ability to charge at home may be easier to overcome by installing public charging points, compared to the barrier of range anxiety. A larger expansion of charging infrastructure would in that case be required in order to overcome the barrier of range anxiety and to increase the BEV adoption in rural areas.

In the full sample regressions in Table 4, parking benefits do not show robust results; especially when including control variables. However, when using sub-samples and the inclusion of control variables, the estimated coefficient for parking benefits in the suburban sample is positive and significant at a one and five percent level in the $\mathrm{FE}$ and $\mathrm{RE}$ regressions, respectively. It is reasonable that the effect is greater in suburban areas than in rural areas since, as hypothesised, the effect is likely to be higher in municipalities with limited and expensive parking than in municipalities with cheaper and more easily available parking. Therefore, the insignificant coefficient of parking benefits in the urban sample is unexpected. This result may however be explained by the regulation against parking benefits of EVs, which may confound the true effect of parking benefits as a policy instrument. Furthermore, the insignificant effect of parking benefits in urban areas can likely be explained by a quicker adjustment to the regulation in these municipalities than in suburban municipalities. The average development of the parking benefits variable for the urban and suburban sample, found in Figure 4 in Appendix A, show that the urban sample has a clear negative trend while the suburban sample in fact has a clear positive trend. Hence, these graphs help explain the regression results and support the argument of a quicker adjustment to the regulation in urban municipalities compared to suburban municipalities, on average.

The estimated coefficient for the procurement proxy is positive and significant in the rural sample at a five and one percent level in the $\mathrm{FE}$ and $\mathrm{RE}$ models, respectively. It is further significant at a ten percent level in the urban sample in the RE model. The result of a higher economic impact of municipally owned BEVs in rural municipalities is in line with our hypothesis. One interpretation, connected to the DoI model, is that the municipally owned BEVs are more visible to the public in smaller communities and therefore receive more attention than in larger communities. The magnitude of the coefficient is further indicated to be larger than that of charging infrastructure in the rural sample. Hence, even though both have a positive impact, visibility of BEVs in rural areas is indicated to have an even higher effect on the BEV adoption than charging infrastructure.

For both the FE and RE models, the variable for Green Party votes is a positive and statistically significant predictor of BEV share in the urban and suburban samples. The average income is further positive and statistically significant in the suburban sample. 
Thus, municipalities with higher average income and Green Party votes are expected to have higher BEV shares, in their respective samples. Furthermore, education is a positive and statistically significant predictor in the rural sample, but only for the RE model. Hence, higher education is indicated to be a determinant of BEV adoption in rural municipalities. As previously mentioned, one explanation for the insignificant predictors in the FE models while significant in the RE models can be too little variation over time, in which the standard errors for the FE coefficients often are large (Allison, 2009).

AVKT is a significant predictor of BEV share in most samples. The impact of higher AVKT is positive in the urban sample and negative in the suburban and rural samples. Among the urban municipalities, people are expected to travel shorter distances on average, as descriptive statistics show in Table 3, and may therefore have less range anxiety related to BEVs. For the suburban and rural municipalities, with higher AVKT on average, the barrier of range anxiety is likely more evident and therefore associated with lower BEV adoption. The statistically significant coefficients for the population density variable are associated with different signs depending on the sub-sample. For the urban and rural samples, the FE models show positive signs, while the suburban sample in the RE model show a negative sign. The economic significance for all coefficients of the population density variable is however close to zero. The time trend coefficient is further positive and significant in most models and the same reasoning holds as in the full sample regressions. Finally, the R-squared measures for the sub-sample regressions indicate that the urban models explain most of the variation in BEV share, while the rural models explain the least.

\subsection{Robustness and sensitivity checks}

To investigate the robustness and sensitivity of our results, we try different model specifications, as well as using an Instrumental Variable (IV) approach. First, in Table 7 in Appendix B, we run the regression according to the model specification in equation (7) but with alternative estimators; the Pooled OLS and the Between Estimator. The Pooled OLS estimator assumes no unobserved individual-specific heterogeneity by pooling the data across time, and it hence ignores the panel structure of the data. The Between Estimator only exploits the cross-sectional variation by reducing the panel data to a cross-section of averages over time, simply becoming an OLS regression between municipalities (Baltagi, 2005). The economic and statistical significance of the charging and procurement estimates are close to identical to the main regression results in Table 4. Furthermore, the coefficient for parking benefits shows insignificant results, similar to 
our main regressions results, implying robustness in our results.

The sensitiveness of the coefficients for the main explanatory variables, when adding additional variables to the regressions, is presented in Table 8 in Appendix B. When adding the time trend variable to the regressions, the magnitude of the coefficients for both charging and the procurement proxy decrease substantially but the statistical significance does not change. When adding the rest of the control variables, both coefficients remain stable; indicating that the economic and statistical significance of the variables are not sensitive for the inclusion of additional variables. The coefficient for parking benefits is also stable when adding control variables since it stays insignificant through almost all model specifications.

To further investigate the robustness of our results, we estimate the regression using alternative versions of the dependent variable. In addition to our standard dependent variable (BEV share in log-form), Table 9 in Appendix B contains FE and RE regressions using BEV share in level form, BEVs per capita in log-form, and EV share in log-form as dependent variables. The coefficient for charging remains relatively stable but decreases slightly in magnitude, especially when using EV share as dependent variable. However, when using EV share as dependent variable, it is reasonable that the effect of charging is smaller since HEVs and PHEVs are included, which are not as dependent on charging infrastructure as BEVs are. In contrast to the other model specifications, the parking benefits coefficient is positive and statistically significant in the FE regression using EV share as dependent variable. This result is also reasonable since parking benefits cover all EVs and the effect should therefore be more evident in this model. The coefficient for the public procurement proxy stays robust using EV share as dependent variable, but when using BEV share in level form as dependent variable the magnitude and the statistical significance decrease. However, as discussed in section 4.2, the BEV share in log-form better fulfils the underlying assumptions of the model and it should therefore yield more correct results. The coefficient magnitude for the procurement proxy further becomes larger using BEVs per capita as dependent variable with a significance level at one percent, both in the FE and the RE models. To sum up, the estimations with alternative dependent variables show results in line with our main results in Table 4 and 5, implying robust results.

The dependent variable, BEV share, is bounded since it in level form only can take values between 0 and 100. The linear model might thus predict values that are nonsensical, such as values that are lower than 0 or higher than 100 . However, this may not be a problem if the dependent variable is normally distributed, and as mentioned in section 4.2, the BEV share distribution becomes approximately normal when transforming 
it into logarithmic form. Furthermore, since the variable of BEVs per capita is not bounded, we use it as an alternative dependent variable mainly to investigate any potential problems (Table 9 in Appendix B). Except from a slightly smaller economic impact of the charging variable and a slightly larger impact of the procurement proxy in the FE and $\mathrm{RE}$ regressions using the unbounded dependent variable, they show similar results. This implies that we do not have problems with the bounded dependent variable.

Since there is no evidence of a direct causal effect of charging infrastructure on the $\mathrm{BEV}$ share, there is a risk of reverse or simultaneous causality bias in our regressions. To investigate this potential endogeneity problem, we estimate an IV regression, presented in Table 10 in Appendix C. The instrument is the amount of issued support, from the so called Klimatklivet, that municipalities have received to install new charging infrastructure (Swedish Environmental Protection Agency, 2017). Klimatklivet is an initiative aimed at providing support for local climate investments to reduce emissions.

The two conditions of instrumental relevance and exogeneity need to be fulfilled for the instrument to be valid (Stock \& Watson, 2012). To fulfil the relevance condition, the instrument should be correlated with the number of public charging points. In the first stage regression, the coefficient for the instrument can be rejected at a 1.1 percent significance level, indicating that the instrument explains some of the variation in the charging variable. The second condition of exogeneity implies that the instrument is uncorrelated with the error term, which cannot be tested since the error term is unobserved. For this condition to hold, the instrument should only affect BEV share through the variable of public charging. We argue that this should be the case and that the instrument rather affects the number of charging points that are installed locally, which in turn affects the BEV share. In summary, our instrument explains some of the variation in the public charging variable, and can be argued to not affect the BEV share in other ways than through public charging infrastructure, which indicates it to be a valid instrument. By using the two stage least squares estimator and a likely valid instrument, it isolates the exogenous part of the charging variable from the potential endogenous part.

A limitation with using this instrument is that data from Klimatklivet only is available for 2016, making the IV regression a cross-sectional regression for the year 2016 instead of a panel regression. The IV approach is therefore mainly a robustness check in order to investigate tendencies of the causality direction. The results of the estimated IV regression show a positive coefficient for charging infrastructure, significant at a five percent level. The magnitude is larger than in the main regressions, which may be explained by the limitation to the year of 2016. Furthermore, as mentioned in section 4.2, cross-sectional regressions that do not control for individual heterogeneity run the risk of obtaining biased 
results. The positive sign and the statistical significance are however in line with our main results. Therefore, the IV approach indicates a causal relationship where charging points are the cause and the BEV share is the effect.

\section{Discussion}

According to our results, the local policy instrument of public charging infrastructure has a significant and positive impact on the BEV adoption rate and it is also found to affect the BEV adoption to a higher degree in urban municipalities than in suburban and rural municipalities. In line with our first hypothesis, this implies that by developing public charging infrastructure, the barriers of range anxiety and limited charging possibilities decrease which, in turn, increase the utility of owning a BEV. Furthermore, differences in the expansion of public charging infrastructure across municipalities could explain why the diffusion of BEVs is faster in some municipalities while others fall behind. In line with our second hypothesis, the ability to overcome barriers of BEV diffusion is further indicated to differ between municipalities since the effect of charging infrastructure is higher in urban municipalities than in other municipality types. Therefore, to achieve an effective implementation of public charging infrastructure, the placement of charging points should be based on the municipality type. Since the main rural barrier connected to charging possibilities is range anxiety, public charging points in rural municipalities should ideally be placed in areas to where people travel on a daily basis. In contrast, since the main urban barrier is limited charging possibilities at home, public charging points in urban municipalities should also be placed close to highly populated areas with limited charging infrastructure.

The impact of parking benefits on the BEV share is, according to our results, positive but not robust. The Supreme Administrative Court's decision of prohibiting municipalities from offering parking benefits towards 'green' vehicles may partly explain these results. However, providing free parking for BEVs is likely less expensive and politically more feasible than, for example, financial incentives such as subsidies for BEVs. Parking benefits as a policy instrument could thus be a relatively cheap approach of increasing the relative advantage of BEVs compared to ICEVs, especially in municipalities where parking is expensive and limited. Reducing the possibilities for municipalities to offer parking benefits for 'green' vehicles may therefore aggravate the transition towards a fossil independent vehicle fleet.

Municipalities using BEVs in their own work can, according to the results, be expected to have higher BEV shares in total, especially in rural municipalities. This result is in 
line with our hypotheses and can be explained with help of the DoI model, in which it is argued that the higher the observability of an innovation is, the higher the adoption rate will be (Rogers, 2003). Since the knowledge about BEVs in Sweden is limited (Swedish Energy Agency, 2014), the aspect of observability can be expected to have an especially high impact. The observability of BEVs, closely related to the neighbourhood effect, implies that a higher influence upon individuals from municipally owned BEVs is likely to increase the knowledge and social acceptance of BEVs. Municipalities that use BEVs in their own work are thus indicated to create a positive externality of knowledge spill-overs when spreading valuable information to non-adopters. The higher effect in rural areas is also reasonable since municipally owned BEVs may be more visible and receive more attention in smaller communities, whereas they may not stand out as much in larger communities. Since this finding is new in the research area, it could have important implications for policy makers. Our findings suggest that a stricter public procurement regulation including BEVs has the potential to be an effective policy instrument to increase the BEV adoption. However, how large the share of BEVs in the municipality vehicle fleet should be is beyond the scope of this thesis.

An alternative explanation to the positive impact of the procurement proxy could be that municipalities having BEVs in their own vehicle fleet also have a 'green' profile in general. A more environmentally engaged municipality may both purchase BEVs to their own work and promote BEVs through other activities. The relationship would, in that case, be a correlation rather than a causal relationship. Either way, increased observability and information can be expected to increase the overall BEV share in municipalities. Even if a regulation regarding public procurement may not be politically feasible in the close future, other measures could be taken in order to improve the information and visibility of BEVs. For example, starting vehicle-sharing fleets of BEVs in municipalities could be an effective way of increasing the knowledge since it would allow people to gain experience with driving BEVs. Another relatively simple measure to increase the observability of BEVs, already implemented in Norway, is to use special license plates for BEVs. Finally, the charging points should also, regardless of the municipality type, be installed where they are visible to the public in order to increase the effectiveness of the policy instrument.

According to neoclassical theory, individuals maximise their utility when making economic decisions. Since the theoretical framework of this thesis is based on the assumption of utility maximising individuals, the slow rate of BEV adoption would be explained by most individuals getting higher utility from purchasing ICEVs than BEVs. However, the neoclassical theory further suggests that profitable innovations should be adopted instantaneously (Manuelli \& Seshadri, 2014). Therefore, since the TCO is lower for BEVs than 
for ICEVs, and if only taking costs into account, the utility of purchasing a BEV should be higher than that of an ICEV, assuming perfect substitutability, rational individuals, and perfect information. As BEVs and ICEVs have become closer substitutes over time, due to increased battery capacity and more widespread charging infrastructure, the slow adoption rate may also be explained by market failures. Market failures arise when the necessary assumptions of the neoclassical theory are not met or if there are certain frictions in the market. If some conditions are not met, the market fails to reach the efficient equilibrium. In our case, the most probable reasons for a market failure are externalities, imperfect information, and other distortions related to the vehicle market. Hence, using only neoclassical theory to explain the slow adoption rate might therefore not be sufficient. Furthermore, as discussed in the theoretical framework of this thesis, other factors than costs can affect individuals' utility from purchasing vehicles.

Since the knowledge about EVs generally is low in Sweden (Swedish Energy Agency, 2014), one potential market failure is the existence of insufficient and incorrect information about BEVs, which further contributes to uncertain benefits associated with BEVs. Since our results show that the procurement proxy has a significant and positive effect on the $\mathrm{BEV}$ adoption, this indicates that municipalities that are using BEVs may spread more knowledge about BEVs than other municipalities. Hence, lack of sufficient information can be an explanation for the relatively slow adoption rate in Sweden since individuals' utility maximising choice may not be based on the correct information.

In case the negative externalities from the use of ICEVs, such as GHG emissions and air pollution, are not fully internalised into the price of ICEVs, another market failure will arise and more ICEVs will be used than what would be efficient from a welfare point of view. Even though the carbon tax in Sweden is high compared to other countries, implying that the negative externalities to a high extent are internalised, the initial purchasing price is substantially higher for a BEV than for an equivalent ICEV. Hence, despite the lower TCO of BEVs, BEVs may be perceived as more expensive than ICEVs. Adding other barriers, such as fewer charging points than conventional petrol stations and range anxiety, individuals may not perceive ICEVs and BEVs as close enough substitutes, which also may be a reason for the slow adoption rate.

Even though the Swedish policy instruments in our results show a positive effect on the BEV share, the slow adoption rate can be an indication of too weak policy incentives in Sweden. As Norway and Sweden are rather similar countries, in the context of for example climate, culture, and socio-economic factors, they should have similar possibilities to promote and increase the share of BEVs. A deeper comparison between the policy instruments in Sweden and Norway could therefore help to increase the understanding of 
what types of incentives that are the most effective in to promoting BEVs. According to Harrysson et al. (2015), Norway offers both higher financial incentives for BEVs and also more used-based policy incentives than Sweden does. Norway can therefore be assumed to have succeeded better with increasing the relative advantage of BEVs, while Swedish individuals may not perceive BEVs to be beneficial enough to cope with the barriers connected to BEVs. Therefore, we need policies that can eliminate or compensate these market failures and make BEVs and ICEVs closer substitutes. Direct subsidies for BEVs can be both costly and ineffective if the BEVs still remain too expensive for most consumers (Bakker \& Trip, 2013), which have been found to be the case with the Swedish green car rebate (Huse \& Lucinda, 2014). Therefore, by complementing the national financial incentives with relatively cheaper alternatives, such as used-based incentives, more charging infrastructure, and providing more information, the BEV adoption could likely be promoted in more effective ways. Moreover, an inequality issue related to the promotion of BEVs may arise since the policy instruments that decrease the cost of BEVs may primarily benefit the already wealthy individuals. This aspect should therefore be taken into account when implementing policy instruments.

When designing and choosing to implement policy instruments, it is important to consider the effectiveness and the feasibility of each instrument. The target of a fossil independent vehicle fleet by 2030 is the desired goal, and achieving that with a set of policy instruments at the least cost would be the most cost-effective solution. As our findings suggest, different municipality types should ideally use different strategies in order to promote BEVs in an effective way. Improving the Swedish local policy instruments could thus be a way forward in order to accelerate the transition towards a fossil independent vehicle fleet.

\section{Conclusion}

In this thesis, we examine the determinants of BEV adoption, with a focus on the impact of local policy instruments. We contribute with important implications for policy makers aiming at promoting the transition towards a fossil independent vehicle fleet, where an increased BEV share is a highlighted solution. We find that an increased number of public charging points has a statistically significant and positive impact on the BEV adoption, especially in urban municipalities. A policy instrument of public procurement of BEVs is also found to positively affect the BEV adoption, especially in rural municipalities. Although the variable for public procurement of BEVs is limited to a proxy, the results are robust and highly significant. Implementing parking benefits for BEVs is indicated to 
have a positive impact on the BEV share, especially in suburban municipalities. However, due to a new regulation against parking benefits for specific vehicle types, this result is less robust. Our findings further suggest that, in order to increase the effectiveness, policy makers should consider local barriers when implementing local policy instruments. For example, by placing the charging points where they are visible to the public as well as taking local conditions into account, it would contribute to an increased effectiveness of the policy instrument.

While this thesis provides new insights regarding BEV adoption and the impact of local policy instruments, it also highlights the need for further research. First, the lack of research regarding public procurement of BEVs as a promising policy instrument and the aspect of political feasibility makes it a relevant subject for future research. Second, the potential problem of reversed causality between the number of charging points and BEV share has not received much attention in related literature. The absence of a causal relationship would have important implications for policy makers since an improved charging infrastructure in that case would not increase the BEV share. We found charging infrastructure to causally affect the BEV share, but since our IV approach is limited, this aspect should be examined more thoroughly in future research.

By implementing local policy instruments, the relative advantage and utility of driving BEVs can be increased, and thus complement the national financial incentives. Moreover, even though the total GHG emissions from ICEVs in Sweden only accounts for a small part of the total global emissions, Sweden has the potential to work as a lead country, showing to other countries that it is possible to reach a fossil independent vehicle fleet. 


\section{References}

Adner, R. (2002). When are technologies disruptive? A demand-based view of the emergence of competition. Strategic Management Journal, 23(8), 667-688.

Allison, P. D. (2009). Fixed Effects Regression Models (Vol. 160). SAGE Publications, Inc.

Axsen, J., Mountain, D. C., \& Jaccard, M. (2009). Combining stated and revealed choice research to simulate the neighbor effect: The case of hybrid-electric vehicles. Resource and Energy Economics, $31(3), 221-238$.

Axsen, J., Kurani, K. S., \& Burke, A. (2010). Are batteries ready for plug-in hybrid buyers?. Transport Policy, 17(3), 173-182.

Bakker, S., \& Trip, J. J. (2013). Policy options to support the adoption of electric vehicles in the urban environment. Transportation Research Part D: Transport and Environment, 25, 18-23.

Baltagi, B. (2005). Econometric analysis of panel data. John Wiley \& Sons, Ltd.

Beresteanu, A., \& Li, S. (2011). Gasoline prices, government support, and the demand for hybrid vehicles in the United States. International Economic Review, 52(1), 161-182.

Berry, S., Levinsohn, J., \& Pakes, A. (1995). Automobile prices in market equilibrium. Econometrica: Journal of the Econometric Society, 841-890.

Bolduc, D., Boucher, N., \& Alvarez-Daziano, R. (2008). Hybrid choice modeling of new technologies for car choice in Canada. Transportation Research Record: Journal of the Transportation Research Board, (2082), 63-71.

Brown, M. A. (2001). Market failures and barriers as a basis for clean energy policies. Energy policy, 29(14), 1197-1207.

Brownstone, D., Bunch, D. S., \& Train, K. (2000). Joint mixed logit models of stated and revealed preferences for alternative-fuel vehicles. Transportation Research Part B: Methodological, 34(5), 315-338.

Cameron, S. (2005). Econometrics. McGraw-Hill Education.

Cameron, A. C., \& Miller, D. L. (2015). A practitioner's guide to cluster-robust inference. Journal of Human Resources, 50(2), 317-372.

Caselli, F., \& Coleman, W. J. (2001). Cross-Country Technology Diffusion: The Case of Computers. American Economic Review, 328-335.

Chandra, A., Gulati, S., \& Kandlikar, M. (2010). Green drivers or free riders? An analysis of tax rebates for hybrid vehicles. Journal of Environmental Economics and management, 60(2), 78-93.

Comin, D., \& Hobijn, B. (2004). Cross-country technology adoption: making the theories face the facts. Journal of monetary Economics, 51(1), 39-83.

Comin, D., \& Hobijn, B. (2010). An Exploration of Technology Diffusion. American Economic Review, 100, 2031-2059.

de Haan, P., Peters, A., \& Scholz, R. W. (2007). Reducing energy consumption in road transport through hybrid vehicles: investigation of rebound effects, and possible effects of tax rebates. Journal of Cleaner Production, 15(11), 1076-1084.

Diamond, D. (2009). The impact of government incentives for hybrid-electric vehicles: Evidence from US states. Energy Policy, 37(3), 972-983. 
Dougherty, C. (2007). Introduction to econometrics. USA: Oxford university press.

Egbue, O., \& Long, S. (2012). Barriers to widespread adoption of electric vehicles: An analysis of consumer attitudes and perceptions. Energy policy, 48, 717-729.

Eppstein, M. J., Grover, D. K., Marshall, J. S., \& Rizzo, D. M. (2011). An agent-based model to study market penetration of plug-in hybrid electric vehicles. Energy Policy, 39(6), 3789-3802.

Gallagher, K. S., \& Muehlegger, E. (2011). Giving green to get green? Incentives and consumer adoption of hybrid vehicle technology. Journal of Environmental Economics and management, 61(1), 1-15.

Harrysson, S., Ulmefors, M., \& Kazlova, A. (2015). Overview and analysis of electric vehicle incentives applied across eight selected country markets. H. Ny, ed., Karlskrona. Available at: http://www.diva-portal.org/smash/record.jsf?pid=diva2:882227 [Accessed: 2017-03-16].

Heffner, R. R., Kurani, K. S., \& Turrentine, T. (2005). Effects of vehicle image in gasoline-hybrid electric vehicles. UC Davis Institute for Transportation Studies, Davis.

HFD 2014 ref 57. En kommuns beslut om att parkeringsavgift inte ska tas ut för miljöbilar har ansetts strida mot lag. The Supreme Administrative Court, Gotland 2014.

Hidrue, M. K., Parsons, G. R., Kempton, W., \& Gardner, M. P. (2011). Willingness to pay for electric vehicles and their attributes. Resource and Energy Economics, 33(3), 686-705.

Huse, C., \& Lucinda, C. (2014). The market impact and the cost of environmental policy: Evidence from the Swedish green car rebate. The Economic Journal, 124(578), F393-F419.

IEA. (2009). Technology Roadmap: Electric and plug-in hybrid electric vehicles. OECD/IEA, Paris. Available at: http://www.iea.org/publications/freepublications/publication/technology-roadmapelectric-and-plug-in-hybrid-electric-vehicles-evphev-html [Accessed: 2017-03-16].

IEA. (2013). Global EV Outlook: Understanding the Electric Vehicle Landscape to 2020. Available at: https://www.iea.org/publications/freepublications/publication/GlobalEVOutlook_2013.pdf [Accessed: 2017-03-16].

IEA. (2016). Global EV Outlook 2016: Beyond one million electric cars. IEA Publishing. Available at: https://www.iea.org/publications/freepublications/publication/Global_EV_Outlook_2016.pdf [Accessed: 2017-03-16].

Jaffe, A. B., Newell, R. G., \& Stavins, R. N. (2005). A tale of two market failures: Technology and environmental policy. Ecological economics, 54(2), 164-174.

Kahn, M. E. (2007). Do greens drive Hummers or hybrids? Environmental ideology as a determinant of consumer choice. Journal of Environmental Economics and Management, 54(2), 129-145.

Langbroek, J. H., Franklin, J. P., \& Susilo, Y. O. (2016). The effect of policy incentives on electric vehicle adoption. Energy Policy, 94, 94-103.

Leiby, P., \& Rubin, J. (2004). Understanding the transition to new fuels and vehicles: lessons learned from analysis and experience of alternative fuel and hybrid vehicles. The Hydrogen Energy Transition, 191-212.

Manuelli, R. E., \& Seshadri, A. (2014). Frictionless technology diffusion: the case of tractors. The American Economic Review, 104(4), 1368-1391.

Mau, P., Eyzaguirre, J., Jaccard, M., Collins-Dodd, C., \& Tiedemann, K. (2008). The 'neighbor effect': Simulating dynamics in consumer preferences for new vehicle technologies. Ecological Economics, 68(1), 504-516. 
Mersky, A. C., Sprei, F., Samaras, C., \& Qian, Z. S. (2016). Effectiveness of incentives on electric vehicle adoption in Norway. Transportation Research Part D: Transport and Environment, 46, 56-68.

Mueller, M. G., \& de Haan, P. (2009). How much do incentives affect car purchase? Agent-based microsimulation of consumer choice of new cars - Part I: Model structure, simulation of bounded rationality, and model validation. Energy Policy, 37(3), 1072-1082.

National Institute of Economic Research. (2013). Miljö, ekonomi och politik. ISSN 2001-3108.

Nord Pool. (2017). Market data, Elspot prices. Available at: http://www.nordpoolspot.com/Marketdata1/Elspot/Area-Prices/SE/Yearly/?view=table [Accessed: 2017-04-06].

Power Circle. (2017). Statistics on charging stations from contact with Mazdak Haghanipour. Available at: http://powercircle.org/kontakt/ [Accessed: 2017-04-05].

Rogers, E. (2003). Diffusion of Innovations, 5th edition, The Free press, New York, NY.

SFS 2011:846. Lag (2011:846) om miljökrav vid upphandling av bilar och vissa kollektivtrafiktjänster.

Sierzchula, W., Bakker, S., Maat, K., \& van Wee, B. (2014). The influence of financial incentives and other socio-economic factors on electric vehicle adoption. Energy Policy, 68, 183-194.

SKL. (2017). Kommungruppsindelning 2017. Available at: https://skl.se/tjanster/kommunerlandsting/fa ktakommunerochlandsting/kommungruppsindelning.2051.html [Accessed: 2017-04-05].

SOU 2013:84. Fossilfrihet på väg. Betänkande av Utredningen om fossilfri fordonstrafik. Stockholm.

SPBI - Svenska Petroleum \& Biodrivmedel Institutet. (2017). Statistik, Skatter. Available at: http://spbi.se/statistik/skatter-2/skatter/?df0 $=2010 \& d t 0=2016 \&$ unit $0=1 \&$ ts $0=0$ [Accessed: 2017 04-06].

StataCorp. (2013). Stata 13 Base Reference Manual. College Station, TX: Stata Press.

Statistics Sweden. (2017). Statistikdatabasen. Available at: http://www.statistikdatabasen.scb.se/pxweb/ sv/ssd/?rxid=0ae184e4-0472-4fe6-974c-57e43d529f28 [Accessed: 2017-04-05].

Stock, J. H., \& Watson, M. M. (2012). Introduction to Econometrics. England: Pearson Education Limited.

Swedish Energy Agency. (2014). Attitydundersökning av svenskars kunskaper om och inställning till elfordon. Available at: http://www.energimyndigheten.se/nyhetsarkiv/2014/forutsattningar-foratt-elfordon-ska-fa-genomslag/ [Accessed: 2017-03-14].

Swedish Energy Agency. (2016). Nulägesrapport inom samordningsuppdraget fossilfri transportsektor. ISSN 1403-1892. Eskilstuna.

Swedish Energy Agency. (2017). Statistik - Transport. Available at: http://www.energimyndigheten.se/ statistik/transport/ [Accessed: 2017-04-26].

Swedish Environmental Protection Agency. (2017). Resultat för Klimatklivet: Beviljade ansökningar från Klimatklivet - fördelade per län samt per åtgärdskategori. [Accessed: 2017-04-21].

Trafikanalys. (2017). Statistik vägtrafik - Fordon på väg. Available at: http://www.trafa.se/vagtrafik/ fordon/ [Accessed: 2017-03-14].

Transportstyrelsen. (2017). Statistics on municipally owned vehicles from contact with Siv Heldert. [Accessed: 2017-04-21].

Wooldridge, J. M. (2010). Econometric analysis of cross section and panel data. England: The MIT press. 


\section{Appendices}

\section{A. Descriptive statistics}
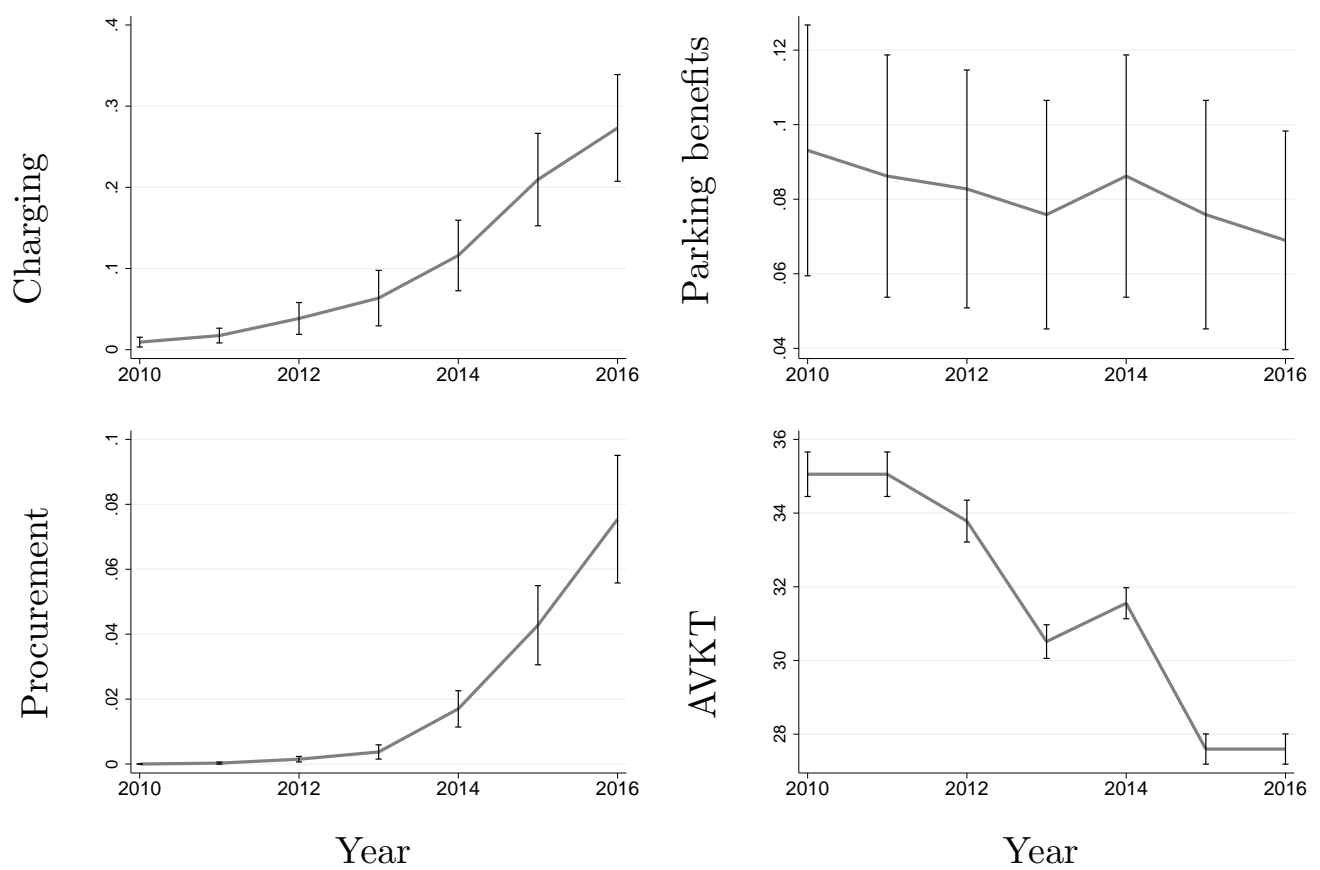

Figure 2: The average development of the most relevant explanatory variables over time. The y-axes of the graphs are the following: Charging is the no. of public charging points per 1,000 inhabitants, Parking benefits is the percentage of municipalities offering parking benefits, Procurement is the no. of municipally owned BEVs per 1,000 inhabitants, and AVKT is the average per day.

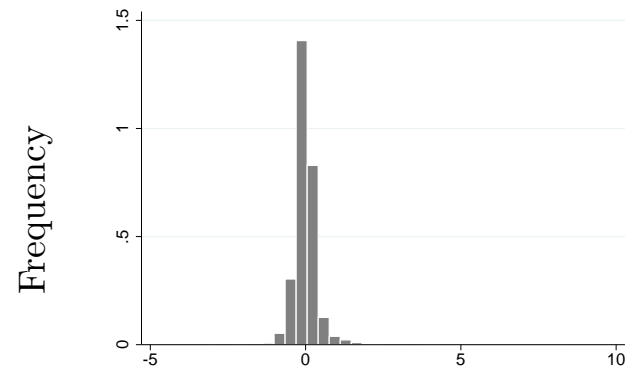

Residuals before log-transformation

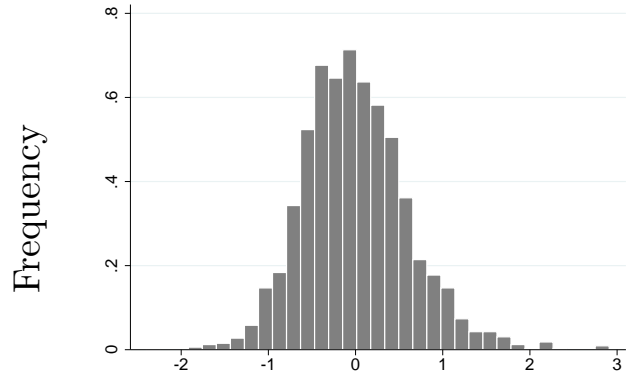

Residuals after log-transformation

Figure 3: Histograms of the distribution of the residuals before and after transforming the dependent variable, $\mathrm{BEV}$ share, into natural logarithmic form. The left graph represents $\varepsilon_{m t}$ before transformation and the right graph represents $\varepsilon_{m t}$ after transformation. 
Table 6: Correlation matrix.

\begin{tabular}{|c|c|c|c|c|c|c|c|c|c|c|}
\hline & 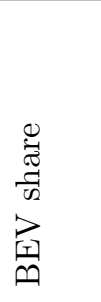 & 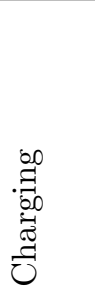 & 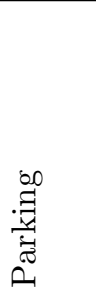 & 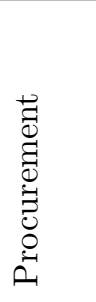 & 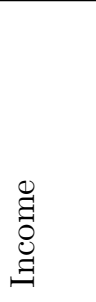 & 苗 & 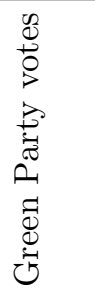 & 喪 & 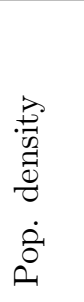 & $\stackrel{\dot{\widetilde{D}}}{\nu}$ \\
\hline BEV share & 1.00 & & & & & & & & & \\
\hline Charging & 0.37 & 1.00 & & & & & & & & \\
\hline Parking & 0.03 & 0.06 & 1.00 & & & & & & & \\
\hline Procurement & 0.18 & 0.19 & 0.05 & 1.00 & & & & & & \\
\hline Income & 0.29 & 0.02 & 0.04 & 0.07 & 1.00 & & & & & \\
\hline Education & 0.18 & 0.06 & 0.31 & 0.06 & 0.66 & 1.00 & & & & \\
\hline Green Party votes & 0.14 & 0.10 & 0.18 & 0.08 & 0.37 & 0.66 & 1.00 & & & \\
\hline AVKT & -0.32 & -0.10 & -0.21 & -0.19 & -0.50 & -0.50 & -0.35 & 1.00 & & \\
\hline Pop. density & 0.06 & 0.01 & 0.09 & 0.00 & 0.34 & 0.51 & 0.39 & -0.34 & 1.00 & \\
\hline Year & 0.43 & 0.25 & -0.02 & 0.28 & 0.32 & 0.09 & 0.08 & -0.54 & 0.01 & 1.00 \\
\hline
\end{tabular}
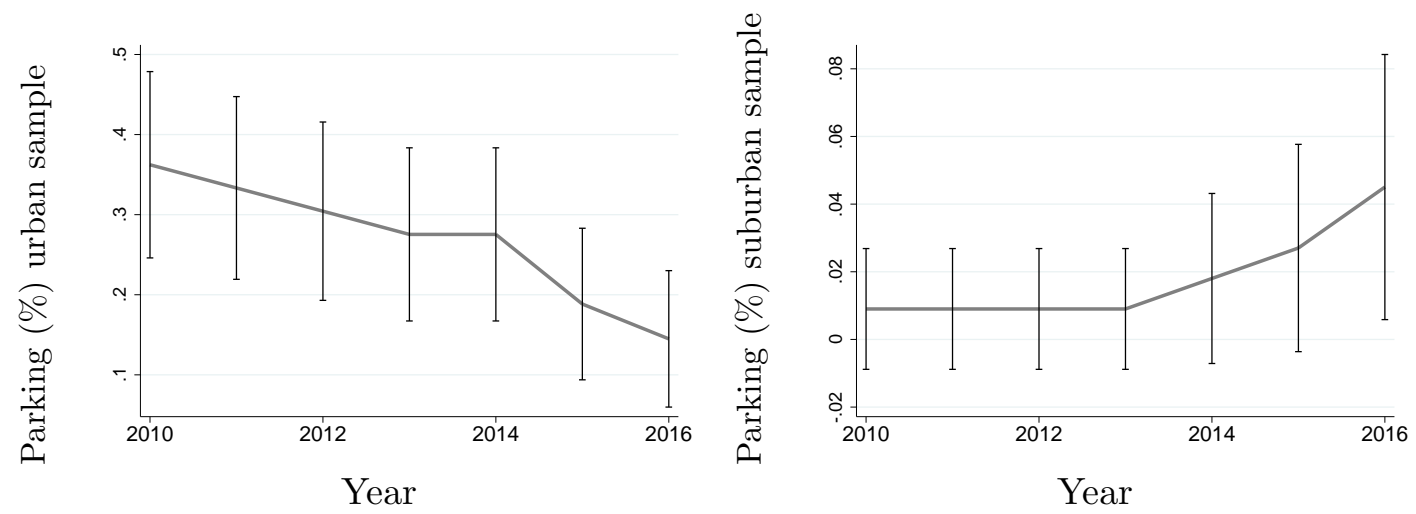

Figure 4: The average development of the parking benefits variable over time, where the left graph represents the urban sample and the right graph represents the suburban sample. 


\section{B. Robustness}

Table 7: Full sample regressions estimated by Pooled OLS and the Between Estimator, using BEV share (ln) as dependent variable.

\begin{tabular}{lll}
\hline & Pooled OLS & Between Estimator \\
\hline Local incentives & & \\
Ln Charging & $0.273^{* * *}$ & $0.275^{* * *}$ \\
& $(0.038)$ & $(0.038)$ \\
Parking & -0.022 & -0.072 \\
& $(0.048)$ & $(0.083)$ \\
Ln Procurement & $0.231^{* * *}$ & $0.255^{* *}$ \\
& $(0.068)$ & $(0.107)$ \\
Control variables & & \\
Income & $0.003^{* * *}$ & $0.002^{* * *}$ \\
& $(0.001)$ & $(0.001)$ \\
Education & $1.136^{* * *}$ & $1.777^{* * *}$ \\
& $(0.431)$ & $(0.556)$ \\
Green Party votes & $0.024^{* * *}$ & 0.012 \\
& $(0.009)$ & $(0.010)$ \\
AVKT & $-0.016^{* * *}$ & $-0.015^{* *}$ \\
& $(0.004)$ & $(0.006)$ \\
Pop. density & $-8.17 \mathrm{e}-05^{* * *}$ & $-7.95 \mathrm{e}-05^{* *}$ \\
Time trend & $(2.65 \mathrm{e}-05)$ & $(3.96 \mathrm{e}-05)$ \\
& $0.190^{* * *}$ & - \\
Constant & $(0.011)$ & - \\
& $-382.800^{* * *}$ & $-1.026^{* * *}$ \\
\hline Observations & $(21.960)$ & $(0.355)$ \\
No. municipalities & 2,030 & 2,030 \\
$R^{2}$ & & 290 \\
\hline & 0.469 & 0.459 \\
\hline
\end{tabular}

Robust standard errors in parentheses.

*** denotes significance at $1 \%$ level, ${ }^{* *}$ at $5 \%$ level, and ${ }^{*}$ at $10 \%$ level. 


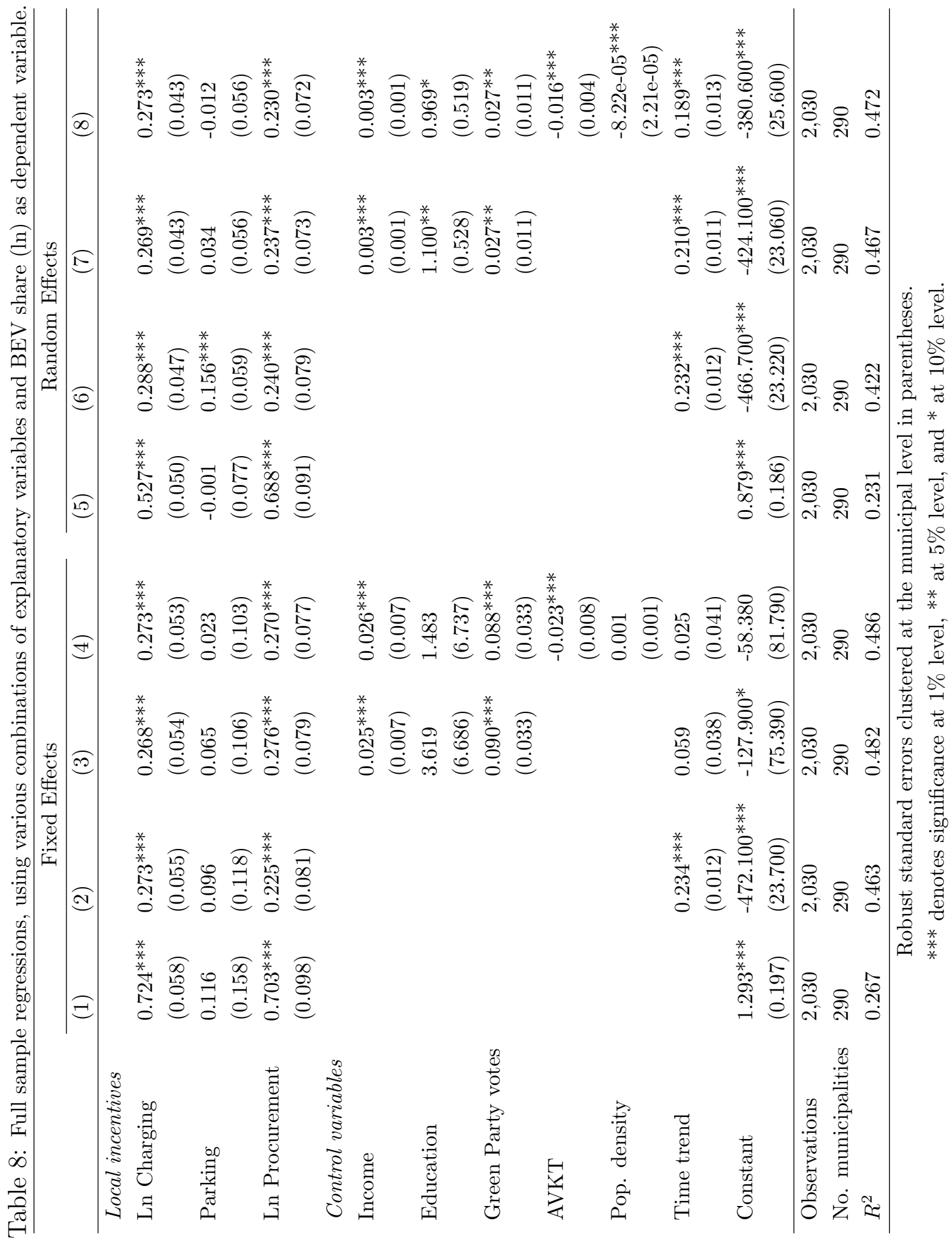




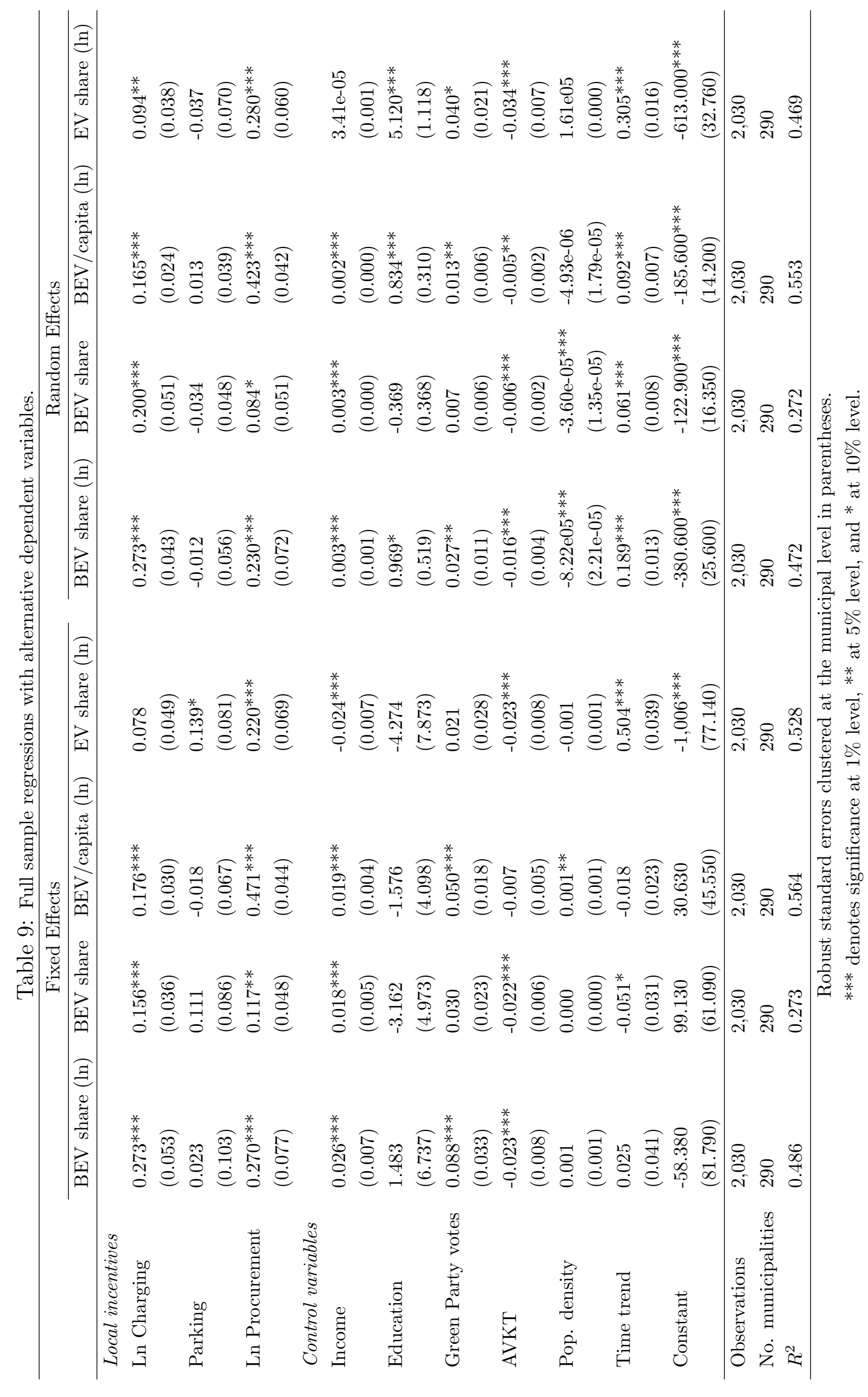




\section{Instrumental Variables regression}

Table 10: Two Stage Least Squares regression using BEV share (ln) as dependent variable and data for 2016.

\begin{tabular}{ll}
\hline & Two Stage Least Squares \\
\hline Local incentives & \\
Ln Charging & $\left(0.661^{* *}\right.$ \\
& -0.105 \\
Parking & $(0.186)$ \\
& -0.143 \\
Ln Procurement & $(0.147)$ \\
& \\
Control variables & $0.006^{* * *}$ \\
Income & $(0.002)$ \\
& 2.037 \\
Education & $(2.030)$ \\
& 0.004 \\
Green Party votes & $(0.032)$ \\
& $-0.042^{* *}$ \\
AVKT & $(0.019)$ \\
& -0.000 \\
Pop. density & $(7.89 \mathrm{e}-05)$ \\
& -1.270 \\
Constant & $(0.850)$ \\
& 290 \\
\hline Observations & 0.139 \\
$R^{2}$ & Robust standard \\
\hline \multirow{2}{*}{$* *$ errors in parentheses. } \\
\end{tabular}

